\title{
EL PARLAMENTO EUROPEO, LEGISLADOR DEL ESPACIO DE JUSTICIA PENAL DE LA UE
}

JUAN FERNANDO LÓPEZ AGUILAR 
SUMARIO

I. EL PARLAMENTO EUROPEO COMO LEGISLADOR PENAL. HACIA UN ESPACIO EUROPEO DE JUSTICIA PENAL. 1. Premisas: la emergencia de la idea de un Espacio Europeo de Justicia Penal. 2. El Tratado de Lisboa y el Espacio de Libertad, Seguridad y Justicia. 3. Derecho Penal Europeo y Espacio Europeo de Justicia Penal. El artículo 83 TFUE como base jurídica para la «lisbonizacion» del Derecho Penal Europeo. 4. Los retos todavía pendientes: el Espacio de Justicia Penal Europeo en perspectiva. 5. Algunas reflexiones conclusivas. II. EL PARLAMENTO EUROPEO COMO LEGISLADOR EN MATERIA PROCESAL PENAL Y EL DERECHO A LA DEFENSA EN EL PROCESO PENAL. 1. Premisas: los derechos de la defensa en el Tratado de Lisboa y la Carta de Derechos Fundamentales de la Unión Europea. 2. El Programa de Estocolmo y los derechos procesales en la Unión Europea. 3. El plan de trabajo para el fortalecimiento de los derechos procesales de las personas sospechosas y del acusado en el proceso penal en la Unión Europea. 4. El derecho al abogado, a la defensa letrada y a la asistencia jurídica. 5. La jurisprudencia del Tribunal de Justicia de la Unión Europea y del Tribunal Europeo de Derechos Humanos sobre el derecho a la defensa y a la asistencia letrada y el derecho a un juicio justo. 6. Algunas reflexiones conclusivas. BIBLIOGRAFÍA. 


\title{
EL PARLAMENTO EUROPEO, LEGISLADOR DEL ESPACIO DE JUSTICIA PENAL DE LA UE
}

\author{
JUAN FERNANDO LÓPEZ AGUILAR \\ Catedrático de Derecho Constitucional, Catedrático Jean Monnet de Derecho \\ europeo y eurodiputado
}

\section{EL PARLAMENTO EUROPEO COMO LEGISLADOR PENAL. HACIA UN ESPACIO EUROPEO DE JUSTICIA PENAL}

\section{Premisas: la emergencia de la idea de un Espacio Europeo de Justicia Penal}

Arranco aquí de una premisa que he sostenido con convicción en numerosas ocasiones: en la construcción de un Espacio de Libertad, Seguridad y Justicia (objeto del Título VI, arts. 67 a 89 del TFUE, según el Tratado de Lisboa (en adelante TL), en vigor desde el 1 de diciembre de 2009) reside la expresión más rotunda de la ambición política y de la dimensión constitucional de la UE. ${ }^{1}$

En efecto, la materia aquí encerrada describe elocuentemente esa naturaleza constitucional: derechos fundamentales (Agencia Europea, Fundamental Rights Agency), ciudadanía, extranjería, asilo, refugio (Agencia EASO), fronteras exte-

${ }^{1}$ Cfr., López Agullar, J. F.: La UE: Suicidio o rescate, Tirant lo Blanch, 2013 pp 19-40 y 83-97; Del mismo autor La aventura democrática, Ed. Peninsula, Madrid, 2009, «El sueño de ser Europa», pp. 177-227; La literatura académica al respecto es ciertamente inabarcable. Basten algunas referencias. Así, Alston P. and Weiler, J. H. H.: "An "Ever closer Union" in Need of a Human Rights Policy», 9 EJIEL, pp. 658-723. BAÑo LEÓN, J. M.: «Los derechos fundamentales en la Comunidad Europea y la competencia del Juez nacional», 54 REDA, 1987, pp. 277-285. CANnizzaro, E.: «Tutela dei diritti fondamentali nell'ambito comunitario e garanzie costituzionali italiana e tedesca», LXXIII Riv. Diritto Internazionale, 1990, pp. 372-379. 
riores de la UE (Agencia Frontex) y libre circulación de personas entre sus Estados miembros (en adelante EE. MM.), cooperación judicial civil, cooperación policial (Europol) y judicial (Eurojust) en materia penal, seguridad interior, legislación penal contra la criminalidad grave transfronteriza y fiscalía europea en la prosecución de objetivos comunes, en la investigación y en la acusación penal contra la criminalidad transnacional y en el combate conjunto a amenazas igualmente compartidas.

Y de todo ello ha venido dando cuenta el formidable despliegue de avances que se han producido en la UE, desde que, precisamente, el TUE de 1992 (conocido como Tratado de Maastricht) introdujo el entonces llamado «Tercer Pilar» (intergubernamental) en materia de Justicia e Interior, por oposición y contraste con el «Primer Pilar» o «Pilar Comunitario» regido por el Derecho común supranacional.

Hasta entonces, los incipientes pasos que se habían registrado en el ámbito del Derecho Penal europeo dimanaban de los Tratados Internacionales suscritos en la materia, en su mayoría promovidos y adoptados en el ámbito del Consejo de Europa. Solo la entrada en vigor del TUE de 1992 (1 de noviembre de 1993), y el posterior Tratado de Ámsterdam (1999, en vigor desde el 1 de mayo de ese año), permitió a los juristas vislumbrar en perspectiva de futuro un emergente proceso europeo de armonización legislativa en materia penal.

Así, el Tratado de Ámsterdam impulsó la conformación del así denominado Espacio de Libertad, Seguridad y Justicia (en adelante ELSJ), orientado a la aproximación de los ordenamientos jurídicos nacionales de los EE. MM. conforme a sus principios jurídicos y tradiciones constitucionales comunes (art. 67.1 TFUE) mediante un itinerario de convergencia y armonización cuyos pilares se sustentarían en los principios de confianza recíproca (mutual trust), reconocimiento (mutual recognition) y cooperación activa (judicial cooperation), sin descartar la adopción de medidas de establecimiento de «reglas mínimas comunes» (minimum rules) (art. 31 del antiguo TUE de 1992) $)^{2}$.

En ese contexto — aunque todavía embrionario, a pesar de la notoria indefinición institucional - se produjeron ya avances muy señalados. En concreto se adoptaron varias decisiones bajo la forma jurídica del instrumento dimanante de

${ }^{2}$ Cfr., por todos, López Agullar, J. F.: «El espacio de libertad, seguridad y justicia», en AA. VV: La Europa de los derechos, Cons. Gral del Notariado, 2004. Achermann, A; Bieber, R.; EPINEY, A.; WeHner, R: Schengen Indie Folgen. Der Abbau der Grenzkontrollen in Europa, Stämpfli, Ber, 1995. BEyAni, C.: Human Rights Standards and the Free Movement of People Within States, Oxford University Press, Oxford, 2000. Collinson, S.: Europe and International Migration, Pinter Publishers, London, New Cork, 1993. Jiménez de PARga Maseda, P.: El derecho a la libre circulación de las personas físicas en la Europa comunitaria, Tecnos, Madrid, 1994. 
la específica modalidad de la cooperación intergubernamental entonces imperante: las Decisiones Marco (en adelante DM) (Framework Decisions). Se trata de normas vinculantes para los Estados que hubiesen optado por ser parte de ese cuadro de honor en la toma de conciencia e implementación de medidas concretamente orientadas a la seguridad común por la vía de la cooperación judicial en materia penal, y de la conformación de un Espacio Europeo de Justicia Penal.

La especificidad de dichas DM residía, en buena medida, en la deferencia a favor de los EE. MM. de la elección de la técnica de transposición normativa para la aseguración del resultado concordado y de su eficacia vinculante.

En este contexto, los pasos más significativos se produjeron en el ámbito de la cooperación judicial. Destacan sobremanera, por su importancia, los avances que se materializaron en torno a los objetivos de la lucha contra el terrorismo. Y ello en el concreto marco de la «internacionalización» de la amenaza terrorista y la conciencia de esta forma de criminalidad especialmente indiscriminada y violenta que sucedió a los históricos atentados terroristas del 11S (2001) en los EE. UU, el 11M (2004) en Madrid y el 7J (2005) en Londres.

Esas fueron las coordenadas que dieron lugar a los progresos de Europol, Eurojust, la «lista» europea de delitos y organizaciones terroristas, y, sobresalientemente, la así llamada «Euroorden» (Orden Europea de detención y arresto, European Arrest Warrant), establecida esta última en las DM 2002/584 y $2009 / 299^{3}$.

A lo largo de ese periodo, bajo la vigencia del Tratado de Ámsterdam y del posterior Tratado de Niza de 2000, y hasta el 1 de diciembre de 2009, fecha esta en la que se produce la entrada en vigor del así llamado Tratado de Lisboa (TL), por el que se cambiarían las reglas de producción de la normativa europea, la UE conocería la adopción de, al menos, 14 DM incidentes en el ámbito de la cooperación judicial en materia penal, así como de al menos otras 16 en los ámbitos del Derecho Penal y del Derecho Procesal Penal.

Otras cinco Directivas adoptadas en ese contexto normativo afectaban, por su parte, al menos en algún aspecto, a la aproximación y/o armonización penal en determinados segmentos de lo que en España denominamos Derecho Penal especial (en los campos de medio ambiente, retención de datos y ciberseguridad,

${ }^{3}$ Vid. por todos, al respecto, Arangüiena, C. (Coord): Cooperación judicial penal en la UE: La Orden Europea de Detención. Ed. Lex. Nov, 2005; y Nieto Martín, A./Arroyo Zapatero, L. (Dirs): La orden de detención y entrega europea, UCLM, 2009; у Вот, S: «Le dialogue entre les juridictions nacionales et la Cour de Justice: L'example du mandat d'arret européen», en Braum, S./Weyembergh, A. (Eds.): Le contrôle juridictionnel Dans l'espace pénale européeen, Institut d'Etudes Européennes, 2009, pp 65-91. 
contaminación marítima, indemnización de víctimas, régimen de inmigración y libre circulación y residencia de personas) ${ }^{4}$.

En otros escritos anteriores me he ocupado de subrayar la magnitud de este acervo. A pesar de la incidencia de la exigencia de la unanimidad y el frente de crítica abierto por las insuficiencias de los «estándares comunes», sus resultados — si bien no plenamente incardinados con lo que en rigor llamamos «método comunitario», por el que se rige la producción de normas inscritas en el Primer Pilar — han sido una muestra formidable de cómo la UE avanzaba no sólo en los planos asociados a la gobernanza del euro y al completamiento del mercado interior, sino también en aquellos otros asociados al Tercer Pilar, estrechamente asociados al núcleo «constitucional» de la ciudadanía y de las libertades.

La imponencia de este acervo nos da una idea aproximada del impacto que la entrada en vigor del TL ha supuesto para el ELSJ ${ }^{5}$.

Como primera nota distintiva, el art. 10 del Protocolo $n^{\circ} 36$ anexo al TL ordena la así llamada «lisbonización» de aquel acervo anteriormente acumulado; esto es, la transposición de las DM al nuevo régimen jurídico del a partir de ahí llamado «procedimiento legislativo ordinario» (procedimiento legislativo por el que se regula la acción legiferante del Parlamento Europeo (en adelante PE), configurado por fin como legislador ordinario de la UE, en una reconversión del antes llamado procedimiento de «codecisión» con el Consejo (art. 289 TFUE) ${ }^{6}$.

Según el propio TL (art. 10 Protocolo 36), todo ello debía hacerse en un plazo de cinco años desde la entrada en vigor del Tratado de Lisboa (esto es, antes del 1 de diciembre de 2014), fecha en que las DM tendrían los mismos efectos que las directivas y la misma sujeción por tanto no sólo a las iniciativas de la Comisión (Art. 258 TFUE) sino a la jurisdicción del Tribunal de Justicia (en adelante TJ) (Título VI TUE). Lo que, en otras palabras, implica la posibilidad de que la Comisión pueda abrir diligencias de procedimiento de infracción contra los EE. MM. eventualmente incumplidores de estas obligaciones ahora comunitarizadas. Y ello quiere decir, a su vez, que el defecto u omisión de la correspondiente transposición de la legislación europea y/o lisbonización por los EE. MM.

4 Para un repaso de esta problemática puede consultarse, con carácter general, la extensa monografía de MuÑoz De Morales Romero, M.: El Legislador Penal Europeo: Legitimidad y Racionalidad, Ed. Civitas/Thomson Reuters, Madrid, 2012, y la bibliografía y jurisprudencia referenciada en esta obra.

5 Cfr. Weyembergh, A./Te Brölley, S.: «Le traite de Lisbonne et la fin annoncé du troisieme pilier: sortie de la crise pour l'espace pénal européen?», en Magrette, P/Weyembergh, A. (dirs): L'Union Europeenne: la fin d'une crise?, Ed. Univ. Brux., 2008.

${ }^{6}$ Vid. sobre estos avances por todos; BAR CEndón, A.: Los Tratados de la UE, Colección Textos Legales, Tirant lo Blanch, 2010. 
podrá dar lugar, en su caso, también al correspondiente procedimiento de infracción por incumplimiento de los mandatos establecidos en el Derecho Europeo.

Como ya se ha señalado, la configuración y desarrollo de un Espacio de Justicia Penal en la UE es sin lugar a dudas uno de los objetivos más ambiciosos del Tratado de Lisboa, y la expresión más genuina de su dimensión política.

Ahora bien, la notoria heterogeneidad de los sistemas penales de los EEMM impone dificultades de envergadura histórica a este empeño de aproximación y de armonización conducente, en términos de horizonte y tendencia, a la construcción a un Espacio de Libertad, Justicia y Seguridad, que cuente entre sus componentes un Espacio Europeo de Justicia Penal.

La primera y primordial de sus dificultades concierne a la concreción de lo que los diferentes Códigos Penales vigentes en los 28 EE. MM. entiendan por «delitos graves» (serious crimes). Pero ello resulta decisivo en tanto esa definición forma parte de la base jurídica consignada en el art. 83 del TFUE como título habilitante para la intervención del PE como legislador penal europeo. La delimitación del alcance, límites de la propia idea de Espacio de Justicia Penal depende las soluciones prácticas que encuentre la aproximación que constituya a sortear este primer escollo.

Una segunda dificultad reside en las estructuras e instituciones competentes para la investigación y enjuiciamiento de delitos (law enforcement agencies), así como su incardinación en redes cooperativas para la persecución de crímenes transnacionales (terrorismo, crimen organizado, cibercriminalidad y blanqueo proveniente de negocios ilícitos). La heterogeneidad de las soluciones organizativas en las escalas nacionales es asimismo notable, sin que resulte posible dictar un único «modelo» o «patrón» comparativo.

La tercera dificultad afecta a los procedimientos. Se observa a aquí la coexistencia de sistemas nacionales de Justicia penal basadas en la especialización orgánica y procesal (como es el caso de España en materia de terrorismo, o Italia en lo relativo a la «criminalitá di stampo maffioso») con otros en los que imperan procedimientos ordinarios. Destaca un subgrupo de países en los que se regulan medidas procedimentales extraordinarias en la intervención de derechos en relación con delitos particularmente graves.

Ahora bien, a la hora de explicar la intervención del PE como legislador europeo en este emergente Espacio de Justicia Penal se perfilan dos supuestos de habilitación primordial.

El primero afecta a los propios intereses de la UE (intereses financieros, aunque no solo), en modo en que la propia UE aparecería como víctima de esos delitos graves. El segundo es el supuesto en que la UE debe intervenir en la medida en que su espacio de libre circulación (bienes, mercancías y capitales, 
servicios y personas) resulte crucial para la materialización de los elementos constitutivos de la delincuencia trasnacional. Ambos requieren y demandan, de consuno, la actuación del PE como legislador penal de una Comunidad de Derecho mediante el específico y cualificado instrumento del Derecho Penal.

Los principios vinculantes de la Carta de Derechos Fundamentales de la UE se aplican aquí plenamente: intervención mínima («ultimo ratio»), necesidad, proporcionalidad y examen de subsidiariedad por los Parlamentos Nacionales de los EEMM (que pueden incoar, no se olvide, la «tarjeta amarilla» o «freno de emergencia» al procedimiento legislativo europeo).

Dichas intervenciones nacionales pueden sustentarse asimismo en el valor jurídico de los derechos fundamentales específicamente consagrados en sus respectivos ordenamientos constitucionales. Y en la específica técnica para su protección, sea en investigaciones mixtas (policía, fiscalía y Poder Judicial), sea en investigaciones dirigidas por el Ministerio Fiscal (prosecutorial), con especial atención a los derechos de las víctimas de los delitos graves, ámbito éste que ha sido objeto ya de iniciativas de armonización tramitadas y completadas por el PE.

También varían grandemente los ordenamientos de los EEMM en lo tocante a la duración de las medidas de detención preventiva, prisión provisional y condenas privativas de libertad. No sólo en duración varían: también en las condiciones materiales de la detención y en la calidad de los establecimientos penitenciarios; este último punto ha dado lugar a un relato de sentencias condenatorias de un buen número de EEMM por el TEDH con sede en Estrasburgo (ej.: STEDH caso Torregani vs. Italia, 2013).

Semejantes divergencias minan la «confianza recíproca» (mutual trust) «y reconocimiento» (mutual recognition) que delinean el sustrato de la cooperación judicial en materia penal entre fiscales, jueces y operadores jurídicos (abogados defensores y de la acusación) de los EEMM.

En concreto, el derecho al abogado (access to lawyer), y a la defensa letrada y a la asistencia jurídica (legal aid), se perfila como uno de los elementos más preciados en la configuración de un Espacio Europeo de Justicia Penal. También aquí, parecen en principio enormes las distancias que habrá que recorrer para aproximar y armonizar las mínimas de cobertura de la asistencia «de oficio» ante la insuficiencia de recursos para litigar. Y, cómo no, habrá que subrayar de nuevo la transcendental importancia que adquiere la idea de ciudadanía europea en la configuración de ese Espacio de Justicia Penal postulado en el TL. Una ciudadanía de identidades superpuestas, geometría variable y derechos complementarios ante sistemas judiciales y jurisdiccionales en diálogo (Poderes Judiciales nacionales, Tribunales Constitucionales, TEDH y TJ). De modo que los derechos 
fundamentales de cobertura nacional interactúan con los consignados en la CDFUE y su ámbito de aplicación (artículos 51-54).

Aspectos, pues, de naturaleza sustantiva se conjugan con otros de derecho procesal, en un continuo de problemas dogmáticos (conceptuales) y prácticos (interpretativos y de aplicación judicial). Pero de lo que no cabe duda es de que sería preciso sortearlo con luz larga de acuerdo con una hoja de ruta para la puesta en marcha del ambicioso plan trazado en el Tratado de Lisboa sin defraudar sus objetivos, y de que el PE habrá de revelarse a lo largo de este íter como legislador penal y procesal penal de alcance paneuropeo.

\section{El Tratado de Lisboa y el Espacio de Libertad, Seguridad y Justicia}

El TL entró en vigor con una incorporación materialmente sui generis de los principales rasgos constitucionales del malogrado Tratado Constitucional (también comúnmente llamada Constitución Europea) que resultó encallado en los sucesivos referendos francés y holandés de $2004^{7}$.

Ello ha supuesto no sólo una reconversión de las herramientas disponibles. Primero, en lo relativo a la seguridad interior en la UE (Título XI TFUE y art. 71 TFUE). También en lo que concierne a las relaciones exteriores incidentes en los ámbitos del ELSJ (al conferir al PE la última palabra sobre la entrada en vigor de los tratados internacionales concluidos por la UE con personalidad jurídica única, art. 218 TFUE). El TL supuso también la actualización y relanzamiento de las reglas de la cooperación policial y judicial en materia penal (arts. 83 a 88 TFUE). Y además, y sobre todo, el impacto de un nuevo régimen de garantías de los derechos fundamentales: la entrada en vigor de la Carta de Derechos Fundamentales de la UE (en adelante CDFUE) «con el mismo valor jurídico de los Tratados» (art. 6 TUE $)^{8}$. Desde un punto de vista sustantivo, la expansión com-

7 Véanse, a este respecto, por toda la inabarcable bibliografía disponible, MANGAS MARTín, A./ Liñán Nogueras, D.: Instituciones, Derecho de la UE, Tecnos, 2010; Roldán Barbero, J.: «La CDFUE, su estatuto constitucional», en Revista de Derecho Comunitario Europeo, n. 16, 2003; y Aldecoa, F., y Guinea Llorante, M.: La Europa que viene: El Tratado de Lisboa, Madrid, Marcial Pons, 2010.

${ }^{8} \mathrm{Vid}$, por toda la bibliografía disponible sobre este concreto aspecto de la dimensión constitucional de la integración europea, SALINAS DE FríAS, A.: La protección de los derechos fundamentales en la UE, Comares, Granada, 2000; Balaguer Callejón, F.: «La Constitución Europea (III): La Carta de los Derechos Fundamentales», en Revista de Derecho Constitucional Europeo n. 4, 2005; «El Tratado de Lisboa en el diván. Una reflexión sobre constitucionalidad, estatalidad y Unión Europea», en REDC n. 83, 2008; «La incidencia del Tratado de Lisboa en el sistema de fuentes de la UE y su influencia en los ordenamientos estatales», en Matía Portilla, F. (dir.): Estudios sobre 
petencial del PE ha elevado hasta más de 80 competencias legislativas la antigua codecisión (antes apenas alcanzaba a 40).

El ELSJ aparece ahora consagrado como objetivo de la UE (art. 3.2 TUE), con pleno respeto a los derechos fundamentales y a los ordenamientos respectivos y tradiciones constitucionales comunes de los EE. MM., sujeto al control judicial encomendado al $\mathrm{TJ}^{9}$.

El ELSJ (Título VI, arts. 67 a 89 TFUE) emerge así como una materia de competencia compartida en la que la iniciativa legislativa de la Comisión (art. 17.2 TUE) aparece compartida con los EE. MM. (art. 76 TFUE: un cuarto de los EE. MM. pueden tomar la iniciativa en esta área, según el TL). El PE puede también, por mayoría de sus miembros, requerir a la Comisión la adopción de iniciativas oportunas para el despliegue de las políticas propias de este campo (art. 225 TFUE). De hecho, una de las novedades institucionales de mayor impacto reside en el sofisticado diseño de relaciones institucionales entre los Parlamentos nacionales y el PE (arts. 69, 70, 71, 85 y 88 TFUE) en materias que habían estado tradicionalmente sujetas al antiguo núcleo duro de la llamada «regalía estatal» (esto es, el ámbito más resistente y protegido de la soberanía legislativa de los EE. MM. $)^{10}$.

De modo que Consejo y PE actúan ahora como colegisladores en pie de igualdad, por mayoría cualificada y procedimiento legislativo ordinario, pudiendo los Parlamentos nacionales interponer, en su caso, un «emergency break» (freno de emergencia o «tarjeta naranja») cuando alguno de ellos considere que la iniciativa legislativa europea afecte a principios esenciales de su sistema judicial, y abriendo también espacio a las cooperaciones reforzadas por, al menos, nueve EE. MM.

Habrá de recordarse, asimismo, cómo que en la fase final de la negociación política conducente a la entrada en vigor del TL tanto el Reino Unido como la República de Irlanda consiguieron afirmar un principio de opting out (a menos que, expresamente, expresen voluntad de opting in en cada específico instrumento), mientras que Dinamarca consiguió su autoexclusión de toda nueva legisla-

el Tratado de Lisboa, Ed. Comares, Granada, 2009; y Cámara Villar, G.: «Los Derechos Fundamentales en el proceso histórico de construcción de la UE y su valor en el Tratado Constitucional», en Rev. de Derecho Constitucional Europeo n. 4, 2005.

9 Véase Sanfrutos Cano; E.: «The Third Pillar and the Court of Justice: A "praetorian communitarization" of police and judicial cooperation in criminal matters», en GUILD, E./GOYER, F.: Security versus Justice?, Ed. Ashgate, 2008.

${ }^{10}$ Vid. Herlin-Karnell, E.: «The Treaty of Lisbon and Criminal Law: Any thing new under the Sun?» en European Journal of Law n ${ }^{\circ} 10,2008$, pp, 32 ss. 
ción que fuese eventualmente adoptada tras el TL en el área de cooperación judicial penal.

En definitiva, con la entrada en vigor del TL, el sistema de «pilares» quedó superado por la generalización del procedimiento legislativo ordinario, con la excepción relevante de lo previsto en el art. 86 TFUE para el establecimiento de una Fiscalía europea (por unanimidad del Consejo o, subsidiariamente, por cooperación reforzada de al menos nueve EE. MM.) y su despliegue progresivo, primero en la investigación de los delitos contra los intereses financieros de la UE, y luego, eventualmente, contra las distintas formas de criminalidad grave transnacional referidas en el art. 83 TFUE.

En cuanto al Derecho Penal sustantivo o material, de un lado, el primer párrafo del art. 83 TFUE prevé una lista de específicos «delitos transfronterizos graves», la cual puede ser ampliada por Decisión unánime adoptada por el Consejo.

De otro, el segundo párrafo del art. 83 TFUE establece una «base jurídica abierta» para la «aproximación» del Derecho penal por vía de «armonización» mediante «reglas mínimas» (minimum rules) en relación a los tipos (criminal offences) y a las penas y sanciones.

El salto cualitativo hacia la conversión del legislador europeo (y, por ende, del PE) en legislador penal ha sido ensayado ya en un conjunto de propuestas de Directive on criminal sanctions for insider dealing and market manipulation (Directiva sobre sanciones penales contra el uso de información privilegiada y manipulaciones del mercado, COM/2011/654, final 2011/0297/COD), así como en las propuestas de Directiva relativas a la protección de los intereses financieros de la UE por vía de medidas y sanciones penales (PIF, COM 363/2912, final 2012/0193 COD) y en la de protección del euro contra sus falsificaciones por vía de medidas y sanciones penales (Directive on the protection of the euro against counterfeiting via criminal law sanctions, COM/2013/42, final COD 2013/0023), ambas en la actualidad en fase primera lectura.

Por su parte, el PE ha insistido en la importancia de los principios de coherencia y sistematicidad en la configuración de su enfoque (approach) del Derecho penal europeo (consistency and coberence) así como en su conformidad a lo dispuesto en la CDFUE (especialmente, del derecho a la no discriminación): Así resulta de la importante y bien trabada Resolución del PE adoptada en Pleno el 22 de mayo de 2012 (Informe de Jong) en respuesta a las Directrices (Guidelines) en materia de Derecho Penal Europeo adoptadas por el Consejo JAI el 30 de noviembre de 2009, y a la Comunicación de la Comisión «Towards an EU Criminal Policy: Ensuring the effective implementation of EU Policies through Criminal Law» (COM/2011/573 final). 
Desde el punto de vista constitucional, toda esta nueva ordenación comporta la actuación de nuevas reglas y principios, carentes hasta ahora de ensayo y por tanto de experiencias; notablemente, en lo relativo a la puesta en funcionamiento de un nuevo instrumento europeo de legislación penal ${ }^{11}$, determinante en todo caso para la configuración de un Espacio Europeo de Justicia Penal.

Lo que quiere decir que, al menos durante el período de transición establecido (hasta el 1 de diciembre de 2014), hemos debido conjugar instrumentos provenientes del antiguo Tercer Pilar (vía intergubernamental, con mera consulta al PE) junto a otros obedientes a las técnicas del Primer Pilar: así coexistirán durante un tiempo relativamente prolongado DM, Reglamentos y Directivas en los ámbitos penal y procesal penal de la regulación de la cooperación judicial en materia penal entre EE. MM. de la UE, con el potencial de contradicción, conflicto o incertidumbre que ello pueda suponer ${ }^{12}$.

Para corroborarlo, son varias las herramientas que, ejemplificativamente ilustran tal complejidad: así, el debate en curso sobre la así llamada Orden Europea de Investigación (EIO), y, sobre todo, la llamada «Hoja de Ruta» del incipiente Derecho Procesal Penal (Procedural Rights Road Map) $)^{13}$.

Piénsese, para comprobarlo, en el momento presente, en la situación que describen las cuestiones relativas al paquete de «Procedural Rights». En síntesis, el cuadro sería el siguiente:

1) La Directiva 2010/64 sobre el derecho a interpretación en los procedimientos penales entró en vigor en octubre de 2010.

2) La Directiva sobre el derecho de información en los procedimientos criminales (2010/0215).

3) El trabajo realizado en el PE (y por su Comisión LIBE, con competencia legislativa sobre Libertades, Justicia y Asuntos de Interior) sobre la propuesta de Directiva relativa al derecho de acceso a un abogado en los procedimientos penales (2011/0154) (cuyo procedimiento legislativo esta en marcha todavía).

11 Cfr. Weyembergh, A./Santamaría, V. (Ed.): The Evaluation of European Criminal Law, Ed. Univ. Brux. Ed, 2009.

12 Vid. LiRola, I.: «La cooperación judicial en materia penal en el Tratado de Lisboa: ¿un doble proceso de comunitarización y consolidación a costa de posibles frenos y fragmentaciones»; Revista General de Derecho Europeo, no 16, Iustel, 2008.

13 Vid., Wolf, S., Goudappel, F. A. N. J./DE Zwaan, J. W.: Freedom, Security and Justice after Lisbon and Stockbolm, The Hague: T. M. C., 2011; SAYERS, D.: «The European Investigation Order: Travelling without a Roadmap», en CEPS Paper in Liberty and Security in Europe, n. 42, CEPS, 2011, Brussels. 
Todo ello ha venido teniendo lugar en el paulatino despliegue del Programa de Estocolmo (2009-2014), así llamado por haber sido adoptado durante la rotatoria Presidencia sueca de la UE (II Semestre 2009), sucesor del pionero Programa de Tampere (Finlandia) (1999-2004) y después del posterior Programa de La Haya (2001-2004).

Pero el TL supone mucho más; muchas y muy serias preguntas, cuestiones y desafíos para el despliegue del impresionante potencial del ELSJ y del Programa de Estocolmo adoptado en $2009^{14}$.

\section{Derecho Penal Europeo y Espacio Europeo de Justicia Penal. El artículo 83 TFUE como base jurídica para la «lisbonizacion» del Derecho Penal Europeo}

Así las cosas, no tardarían en plantearse problemas jurídicos, numerosos y de enjundia. Piénsese en la concreción de lo que deba entenderse por «criminalidad transfronteriza», e incluso «delito grave», o «delito transnacional», en la redacción consagrada en el art. 83 TFUE: la cuestión del contenido y del significado concreto de estas referencias normativas se presta a discusión no sólo doctrinal sino también política, que deberá esclarecerse a través del debate correspondiente en cada caso.

El objetivo debería haberse completado con la «lisbonización» (programa de cinco años para la «reconversión» en nuevas normas europeas del anterior acervo del Tercer Pilar). Lo cierto es que el TL establece con mayor claridad y contundencia que nunca un mandato de cooperación, que deberá ser constante e intensa, entre las instituciones legislativas europeas (la Comisión y el Consejo y el PE) y los Parlamentos nacionales. La cooperación institucional entre legislativos —el legislador europeo y los legisladores nacionales de los EE. MM.- se establece como premisa y presupuesto de la eventual interacción entre las «reglas comunes» europeas y el complemento legislativo que deben asegurar las legislaciones nacionales $^{15}$ de los EE. MM.

Desde un punto de vista sustantivo, el gozne de conexión es el que ofrecía cabalmente ese concepto en principio indeterminado de «reglas mínimas» penales. Un concepto que, no se pierda de vista, no aparecía referenciado como tal en la redacción del TUE, sino que emergió en el posterior Tratado de Ámsterdam

14 Vid. Carrera, S. y Guild, E.: «"Does the Stockholm Programme matter?” (the struggles over Ownership of AFSJ Multiannual Programming», en CEPS Papers of Liberty E Securitas, n. 51, 2012.

15 Vid., sobre estos aspectos, Nilsson, Hans, G.; «How to combine minimun rules with maximum legal certainty», Europarattsilig tidskrift, Arg. 14, 2011 n. 4, pp. 665-677. 
(art. 31.1). De modo que ese primer punto de apoyo sirvió en su momento al Consejo (puesto que entonces el instrumento legislativo era la DM, producto de la cooperación intergubernamental entre EE. MM.) para tomar la iniciativa sobre materias penales de ámbito transfronterizo y sobre «delitos graves» en temas tan poco desdeñables como la corrupción, la explotación de menores o el decomiso de bienes procedentes de negocios ilícitos.

El trayecto descrito hasta la fecha por el historial de DM adoptadas bajo la vigencia del Tratado de Ámsterdam es, ello no obstante, desigual. En algunos casos, cada DM europea manifestó y aun hoy expresa la voluntad legislativa (voluntas legislatoris) de agotar la definición de los elementos constitutivos del tipo (en el caso de la DM sobre tráfico de drogas); en otros supuestos, el margen de maniobra para la complementaria legislación penal nacional se amplía considerablemente. Con todo, de lo que no cabe duda es de que las acciones y conductas descritas en cada correspondiente DM deben ser — en los términos de esta específica herramienta - consecuentemente tipificadas y perseguidas penalmente en los distintos Códigos Penales de los EE. MM. que formen parte de ese esquema de «cooperación reforzada» ${ }^{16}$.

En la perspectiva de futuro, la de la preceptiva pauta de «lisbonización» del entonces acervo del Tercer Pilar, podría pensarse en principio que los EE. MM. pueden siempre ensanchar los elementos constitutivos del tipo penal correspondiente con el plausible objetivo de penalizar un número de supuestos punibles mayor al de los inicialmente contemplados en la «regla mínima penal» de la DM. Un razonamiento más detenido ilustrará, ello no obstante, matices en esta percepción. Porque sigue siendo cierto que buenas razones de seguridad jurídica y coherencia sistémica, que abogan comprensiblemente por la aplicación uniforme del Derecho de la UE (incluidos los relacionados con la unidad de mercado, principio básico del Derecho europeo), aconsejan responder en un sentido muy distinto, tendiendo a una práctica equiparación de una y otra esfera normativa. La misma por la que se superponen y solapan, hasta hacerse difícilmente distinguibles, incluso a identificarse, la llamada «regla mínima» europea y la legislación de transposición estatal.

De este modo, las llamadas «reglas mínimas» en cuanto que reglas comunes podrían incluso expandirse hasta vertebrar un potente eje virtual no sólo en lo relativo a la aproximación entre las legislaciones penales de los EE. MM. sino a la

16 Cfr. Silva SÁnchez, J. M.: «Los principios inspiradores de las propuestas de un Derecho Penal europeo. Una aproximación crítica» en Revista Penal n ${ }^{\circ}$ 13, 2004, pp 138 ss.; BARLETTA, A.: La legalitá penal tra diritto dell' Unione Europea e costituzione, Jovene Editore 2011; Delmas-Marty, M./Pieth, M./Sieber, U. (Dirs.): «Les Chemins de l'harmonisation pénale», UMR, Droit Comparé, Paris, vol. 15, 2008. 
armonización del Derecho Penal de los EE. MM. Lo que quiere decir que, por ahora, el significado concreto de esta técnica de Derecho europeo deberá apreciarse en cada caso concreto, en relación con las iniciativas legislativas de que en los mismos se trate.

Con la entrada en vigor del TL, es más claro que nunca que el Derecho de la UE incide también sobre el Derecho penal sustantivo no sólo en el de factura supranacional europea sino también del dimanante de los respectivos poderes legislativos de los EE. MM. ${ }^{17}$.

Ello involucra, además, el específico impacto del Derecho penal europeo sobre el régimen de garantía y ejercicio de los derechos fundamentales de los ciudadanos europeos. Lo que percute sobre ese nuevo nivel de protección de los derechos fundamentales dimanante de la entrada en vigor de la CDFUE, incorporada a los Tratados con su «mismo valor jurídico» (art. 6 TUE). Derechos fundamentales éstos que, no se pierda de vista, complementan y enriquecen los que los ciudadanos europeos disfrutan ya por ser tales de sus respectivos países de acuerdo con las Constituciones y en los ordenamientos de sus respectivos EE. MM. Ello puede constatarse muy particularmente, al examinar los artículos de la CFDFUE específicamente relativos al despliegue normativo de la garantía de los principios de tutela judicial, del derecho al juez imparcial y de la legalidad penal en el Derecho europeo (arts. 47 a 50 CDFUE). En concreto, los principios de seguridad jurídica; presunción de inocencia y derecho a la defensa; prohibición de doble incriminación y derecho a no ser juzgado o condenado dos veces por la misma infracción (ne bis in idem); no discriminación; proporcionalidad; prohibición de indefensión y prohibición de retroactividad para las normas restrictivas no favorables al reo. Téngase en cuenta, en especial, la particular dimensión que el principio de proporcionalidad incorpora en la materia penal, como ámbito que es diferenciado y autónomo respecto de otras aplicaciones frecuentes de este criterio en el Derecho europeo ${ }^{18}$.

Desde un punto de vista formal, no debe tampoco ignorarse que tanto la Directiva como el Reglamento — que son los nuevos instrumentos legislativos tras la entrada en vigor del TL — poseen, por sus caracterizaciones jurídicas respectivas, efectos vinculantes más inmediatos y directos que las DM. Así, el

17 Vid., por todos, la extensa monografía de MuÑoz DE MORALEs Romero, M.: El Legislador Penal Europeo: Legitimidad y Racionalidad, cit.

18 Vid., GuILD, E.: «Fundamental Rights and EU Citizenship after the Treaty of Lisbon», en CEPS Papers of Liberty and Security in Europe, CEPS, Brussels, 2010; BARLETTA, A.: «Notes sur le contrôle des actes de l'UE par la Cour de Justice des Communautés Européennes dan la matière pénal et le troisième pilier», en Giudicelli-Delage, G./Manacorda, S. (Dirs.): Cour de Justice et Justice Pénale, Unité Droit Comparé, Paris, 2010. 
caso Pupino (TJ, caso 105/03) puso en su día de manifiesto que también las Directivas pueden llegar a desplegar cierta «eficacia indirecta» sobre la legislación de los EE. MM. en la precisa medida en que los juzgadores nacionales deban siempre interpretar el propio Derecho interno desde su conformidad con el Derecho europeo, cualquiera que sea su instrumento (Directiva, Reglamento o DM). De modo que, en otras palabras, no resultan jurídicamente admisibles aquellas interpretaciones efectuadas contra legem contra el Derecho europeo, esto es, en un sentido manifiestamente incompatible con la Directiva de referencia, pero tampoco, a estos efectos, con la DM que resulte en cada caso de referencia.

Por su parte, no puede perderse de vista que las Directivas se distinguen por su carácter vinculante en cuanto a los resultados, defiriendo a los EE. MM. la elección del instrumento y cauce de la transposición, de acuerdo con cada específico sistema constitucional de fuentes de Derecho interno. Ello quiere decir que, en principio, no debería derivarse, sin más, ninguna responsabilidad penal de una determinada DM que no haya sido aún transpuesta en el Derecho interno. Pero también que, en principio, las Directivas requieren la actuación del correspondiente complemento legislativo estatal, conforme a la interpretación general que del principio de seguridad jurídica ha venido estableciendo la jurisprudencia del TJ (así en el Caso Berlusconi: TJ, caso 397/02).

Ello no obsta tampoco a la obligación que asimismo pesa sobre los operadores jurídicos y en especial, los Juzgados y Tribunales de los EE. MM., de interpretar el respectivo Derecho nacional de conformidad con el acervo de las DM (Tercer Pilar) y de las Directivas de referencia en la materia (Primer Pilar), así como, por descontado, de la legislación europea adoptada ya a partir de la entrada en vigor del TL.

A este respecto, los problemas prácticos y operativos no han dejado de multiplicarse. Ello es así especialmente cuando examinamos con detalle los instrumentos específicos con los que la UE ha venido operando hasta la entrada en vigor del TL, sean éstos ya provenientes del antiguo Tercer Pilar, sean éstos del Primer Pilar. Así, por ejemplo, en torno a la crucial DM sobre Terrorismo (2002/475) cabe todavía plantearse numerosas cuestiones de interpretación operativa, singularmente en relación con los conceptos jurídicos incorporados («atentado terrorista», «intimidación grave de la población», «desestabilización grave», «restricción indebida»...). Y lo mismo sucede cuando introducimos los conceptos utilizados en las DM sobre explotación sexual o pornografía infantil, o incluso la DM sobre tráfico de drogas.

Todo lo cual quiere decir que no están todavía despejados, ni mucho menos totalmente, los problemas relacionados con el correspondiente «margen de maniobra» de los EE. MM. 
Lo mismo cabe decir, por ejemplo, en cuanto a la DM sobre Decomiso de los beneficios derivados del delito (Confiscation on the proceeds of crime), discutir hasta qué punto se abren o no espacios de duda razonable en cuanto a la capacidad de los EE. MM. para poder ir más allá de lo establecido en principio en el instrumento europeo en materia de «delito fiscal»y de «lucha contra el fraude», vistos los numerosos y variados tipos de los delitos fiscales que a menudo se cometen como colaterales en el blanqueo de dinero procedente de negocios ilícitos ${ }^{19}$.

Pero, como quiera que sea, lo cierto y fundamental es que el art. 83 TFUE - como una pieza más, por tanto, de la renovación del sistema de fuentes europeo efectuada por el TL — incluye también, por primera vez en la historia de la integración supranacional europea, la innovadora potestad del legislador europeo de establecer nada menos que «penas» y «sanciones» — no sólo, pues, por lo tanto, del elemento constitutivo del tipo-, así como las correspondientes referencias normativas sobre la tipología y el nivel de intensidad de las penas europeas.

Habitualmente se interpreta que ello supone en la práctica fijar en el escalón europeo el «mínimo penológico», pudiendo los EE. MM. aumentar su intensidad de acuerdo con sus propias opciones y prioridades en materia de política criminal.

Es cierto que, hasta ahora, no se ha hecho lo bastante al respecto. Pero es claro que la influencia del nuevo Derecho europeo sobre los EE. MM. ha venido produciéndose en el preciso sentido de propender a incrementar (por tanto, revisar al alza) las penas ya contempladas en sus legislaciones penales obedeciendo a la influencia de la preeminente orientación al respecto de aquellos EE. MM. con experiencia más contrastada en cada determinado ámbito material. Y la razón es simple: en una UE recorrida por sucesivas ampliaciones hacia una mayor complejidad y heterogeneidad de sus ordenamientos y sus culturas jurídicas, no todos los EE. MM. proceden de la misma experiencia ni de la misma cultura de alerta político-criminal, ni de iniciativa, tampoco, frente a determinadas formas de criminalidad grave y transfronteriza (delitos transnacionales).

Es el específico caso del terrorismo. Su amenaza y su violencia han sido en cierto modo ajenas a la cultura y experiencia de un buen número de EE. MM. Y así, durante largo tiempo: piénsese en Luxemburgo, en Finlandia, Austria o Suecia, donde no hubo tratamiento penal específico del terrorismo hasta tiempo muy reciente; por no ampliar el abanico de la triste desventaja de la sobrecualificada experiencia española a este respecto: la nuestra es la única Constitución que, en el marco del Derecho comparado de la UE, recoge en su redacción ori-

19 Vid. Guild, E., Carrera, S., y BalzacQ, T.: «The Changing Dynamics of Security in an Enlarged European Union», en AA. VV.: Europe's 21 ${ }^{\text {st }}$ Century Challenge: Delivering Liberty, Ed. Ashgate Publishing, 2010. 
ginaria (1978, en nuestro caso, en convulsión dolorosamente marcada por sangrientos actos terroristas) nada menos que dos referencias explícitas al terrorismo (arts. 13.3 y 55.2 CE) y al menos otra más elíptica (los «estados» contemplados en el art. $116 \mathrm{CE})$.

En punto a la articulación de una respuesta europea a esta modalidad de criminalidad grave transnacional, es obvio el punto de inflexión que en su día supusieron los atentados yihadistas del 11-S de 2001 en los EE. UU, seguidos por los atentados de Madrid en 2004 (masacre del 11-M) y Londres en 2006. Lo que no empece que, incluso en este marco de comprensión europea de un problema que no puede ser afrontado desde la soledad de ningún Estado miembro, no necesita subrayarse hasta qué punto España — por entendibles motivos- ha sido no sólo pionera en la especialización de sus Derechos penal, procesal, penitenciario y jurídico judicial, sino que ha estado en la vanguardia de cada iniciativa europea en la formulación de una respuesta incidente en la legislación penal y en la cooperación en los ámbitos de inteligencia, policía y fuerzas de seguridad, fiscalía y judicatura.

Por último, procede aquí una referencia a la aproximación del Derecho Procesal Penal de los EE. MM.

El art. 82 TFUE establece a este respecto que la UE legislará los «mínimos necesarios» para facilitar el mutuo reconocimiento de las sentencias y demás resoluciones judiciales; para añadir de inmediato que ello se hará «sin perjuicio de la capacidad de los EE. MM. de mantener o introducir un nivel superior de protección de las personas», lo que resulta coherente con lo dispuesto en los arts. 51 a 54 de la CDFUE, relativos a las reglas para su aplicación judicial por las jurisdicciones de los EE. MM.

Ello quiere decir, contrario sensu, que lo que no se puede hacer es disminuir o rebajar el así denominado mínimo europeo, en la línea señalada hace ya tiempo por el Convenio Europeo de Protección de los Intereses Financieros de la Comunidad, de 1995 (art. 9).

Los ejemplos prácticos abundan a la hora de ilustrar y también en el ámbito del Derecho Procesal Penal que las «reglas mínimas» europeas desempeñan una relevante función aproximativa y/o armonizadora entre los EE. MM. ${ }^{20}$.

Estos ejemplos resultan especialmente expresivos en la interpretación de la llamada «hoja de ruta» de Derechos Procesales (Procedural Rights Road Map) actualmente en curso de tramitación y desarrollo en el PE, en cumplimiento de lo previs-

${ }^{20}$ Cfr. Nieto Martín, A.:»Modeles d'organisation judiciaire dans le droit penal européen», en Giudicelli Delaye, G./Mancorda, S.: Cour de Justice et Justice Pénale, Un. Droit Comparé, Paris, 2010. 
to en el Programa de Estocolmo (2009) y en el subsiguiente Plan de Acción (adoptado en 2010, bajo Presidencia española) por cuyo cumplimiento debe velar la Comisión.

Así, en lo relativo a la obligación de «traducción de documentos en los procedimientos penales», en los que el nivel europeo puede ser superado por la legislación de los EE. MM. Lo mismo sucede en las medidas relativas al «derecho a la información de cualquier acusación formulada en su contra» que asiste a todo encartado en un proceso penal, en el derecho a ser informado de los cargos en su contra «en modo que le sea comprensible», y en lo relativo al derecho de «acceso a la asistencia letrada» y al «derecho a la defensa».

Especial referencia merece también la denominada «cláusula de no regresión» (Non regression clause), por la que, en el ámbito del Derecho Procesal Penal, las llamadas «reglas mínimas» pueden dar lugar no sólo a mejores estándares de protección por parte de los EE. MM., sino también a compromisos de no minoración (Non regression) de los avances producidos en el reconocimiento mutuo de derechos e instrumentos específicos de cooperación judicial en la Justicia penal. Y ello sin perder de vista el objetivo de facilitar el reconocimiento mutuo de actos y resoluciones y el refuerzo continuado de la confianza recíproca entre los Estados requirentes y los Estados requeridos.

A la vista de los avances expuestos hasta aquí, huelga recordar la redoblada importancia que cobrará, una vez más, la relevante cuestión de la formación europea de jueces, de magistrados y de representantes del ministerio público o ministerio fiscal (i.e. la judicial training) ${ }^{21}$.

En otras palabras: no habrá Derecho europeo ni un genuino y operativo Espacio de Libertad, Seguridad y Justicia a lo largo y ancho de la UE sin un esfuerzo sostenido y proporcionado en la formación de operadores jurídicos en el manejo y garantía de su ordenamiento específico.

Ahora bien, como se advirtió previamente, la noción de «delitos graves» (art. 83 TFUE) no encierra un significado jurídico unívoco y uniforme en los EE. MM. Ciertamente, la generalidad de los EE. MM. asumen como objetivo de sus legislaciones penales y políticas criminales la asignación de recursos a la lucha contra el crimen, consignando de un modo u otro su idea de «gravedad» en la amenaza a bienes jurídicos especialmente protegidos. Tal heterogeneidad solo puede ser sorteada, como sugiere el informe De Jong sobre la aproximación y coberencia del derecho penal europeo (2013), mediante una definición autónoma y netamente europea de los «delitos graves», actualizada, junto con el Consejo (colegislador penal), por el PE como legislador penal europeo.

21 Vid. Carrera, S., Guild, E. y Eggenschwiler, A.: "The AFSJ ten years on: Successes and Future Challenges under the Stockholm Programme», CEPS Paperback, 2011. 
Obviamente, el preconcepto de la «gravedad» requiere una opción política, político-criminal. Coadyuva, por un primer lado, a descargar la jurisdicción penal de los asuntos «menos graves» (habitualmente menos complejos), con procedimientos simplificados y potencialmente más eficientes. Pero esa gravedad ha basculado hasta ahora en la legislación de «regalía estatal», reducto de esa «soberanía» que tradicionalmente ha encerrado la legislación penal en los EEMM.

Así, no es de extrañar, que un buen número de EE. MM. recoja en sus Códigos Penales disposiciones especiales para afrontar el terrorismo (Irlanda, Italia, España...), o el crimen organizado (Italia, Reino Unido...), mientras sus legislaciones procesales hacen descansar ese cometido sea en la fiscalía sea en el Poder Judicial.

Los catálogos de «delitos graves» muestran grandes variaciones en función de las culturas jurídicas de referencia (delitos económicos, fraude fiscal, delitos ambientales, falsificación, tráfico de personas, cibercriminalidad, y por supuesto, formas de criminalidad especialmente violenta).

Análogamente el relatorio de instituciones investigadoras contempla fórmulas diversas. El elemento común en perspectiva comparada resulta de la especialización de los procedimientos para bregar con ellos. La consecuencia práctica de la definición nacional del «delito grave» se anuda pues a la especialidad procesal, con exclusión mayoritaria del acuerdo extraprocesal o conformidad con la pena ( «plea bargaining» y «guilty plea»). La especialización extrema incluye la atribución de competencia jurisdiccional a órganos distinguidos en la estructura judicial por esa precisa función (Ej: la Audiencia Nacional en España), y la restricción específica de derechos fundamentales a las personas investigadas (Art. 55.2 CE).

En consecuencia, el horizonte de la aproximación ante estas heterogeneidades se inscribe en un desarrollo genuinamente europeo del artículo 83 TFUE, en corolario a un acervo de cooperación judicial internacional entre EEMM de la UE (Ej: DM Eurojust 2009, DM Europol 2009; la European Arrest Warrant de 2003), cuya culminación debería desembocar en la Orden Europea de Arresto, definitiva puesta en marcha de la Fiscalía Europea (art. 86 TFUE).

El propio art. 83 TFUE provee una indicación clara de esa estimación europea de la especial «gravedad» en crímenes transnacionales: terrorismo, tráfico de seres humanos, explotación sexual de mujeres y niños, tráfico ilícito de drogas, tráfico ilícito de armas, blanqueo de dinero, corrupción, falsificación de pagos, cibercriminalidad, crimen organizado.

En esta relación material de ámbitos cualificados, la UE debe actuar como facilitadora de cooperación judicial entre los EE. MM., que debería dar cobertura en sus ordenamientos nacionales tanto la investigación como la persecución contra los delitos menos graves. Si bien no resulta posible excluir un margen de discreción legislativa nacional, sí que ya existen en cambio, criterios ciertos de 
cobertura (seguridad jurídica, «legal certainity» y «ultimo ratio») para la acción del PE como legislador penal europeo.

Se oponen sin duda a este objetivo los impulsos proteccionistas de la soberanía estatal, rayanos en ocasiones en el reaccionarismo (ej: los nacionalistas británicos). La UE debe ser por tanto deliberadamente cauta con el equilibrio entre EE. MM. y el escalón europeo en el Espacio de Justicia Penal. Y apostar selectivamente por su valor añadido legislativo en el delito de neto alcance trasnacional, ámbito este desbrozado por el Consejo de Europa (Ej: El GRECO contra la corrupción) y por la propia UE (Europol, Eurojust) para apuntalar las áreas en que la UE o bien protege sus propios objetivos distintivos intereses (art. 86 TFUE: sus «intereses financieros») o bien protege penalmente el derecho de ciudadanía europea consagrado en la CDFUE.

Esta delimitación estricta —autoexigente, si se quiere, en términos de self restraint - contribuiría a prevenir cualquier eventual tentación de deslizamiento al terreno de una actuación incursa en ultra vires ( «exceso legislativo» o «desviación de poder»).

De lo que se trata, obviamente, es de acreditar el perímetro sustantivo y procesal (due process of law) para la actuación del Derecho Penal europeo como marco sustantivo para la construcción de un Espacio Judicial Penal que esté sujeto por lo tanto al test de la «gravedad» del delito y su «alcance transaccional».

Lo mismo cabe predicar de la prefiguración de un examen compartido de los derechos procesales y las praxis procesales en el derecho a la defensa letrada ante la Justicia Penal.

Las variaciones aquí son igualmente amplias: reglas de admisión de «pruebas pertinentes para la defensa»: adecuación a derecho de la investigación policial, regla de exclusión de pruebas ilícitamente obtenidas; intervención coercitiva en derechos fundamentales y autorización judicial para determinadas intervenciones (domicilio, inviolabilidad de las comunicaciones...), participación o no de «acusación popular en el proceso penal»).

Son raros, por lo demás, los EEMM que escapan a las condenas del TEDH en la delicada «línea roja» de las circunstancias de la detención, de la «prisión provisional» y de la «privación de libertad, tanto por su duración como por sus condiciones físicas o materiales». La particular importancia de una correcta garantía del derecho al abogado y a la asistencia letrada (art. 77 CDFUE) se redobla en estos puntos extremadamente sensibles.

Y, por descontado, esto es así aún más en todo lo relativo a la jurisdicción penal de menores (Juvenile defendants) y a la necesidad de cubrir todas estas heterogeneidades con una intervención adecuada, proporcional y necesaria, del legislador en la Justicia penal. 


\section{Los retos todavía pendientes: el Espacio de Justicia Penal en perspectiva}

En la legislatura del PE 2009-2014 el ELSJ fue objeto de un desarrollo extensivo e intensivo en el Derecho europeo. Ello resultó especialmente visible en los trabajos del PE. Esta labor se desarrolla de manera principal dentro de la Comisión LIBE (que es como se denomina a la Comisión legislativa responsable de los Asuntos de Libertades, Justicia e Interior). Se trata ésta, además, después de la entrada en vigor del TL, de la Comisión con mayor carga de trabajo legislativo: ciudadanía, extranjería, asilo y refugio en la UE; gestión de fronteras exteriores y libre circulación de personas; cooperación judicial en materia civil y cooperación policial y judicial en materia penal; seguridad interior; legislación penal contra la criminalidad grave transfronteriza; protección penal frente a los atentados contra los intereses de la UE y fiscalía europea.

Durante la legislatura 2009-2014 la tarea legislativa de la Comisión LIBE se desplegó sobre el conjunto de los elementos componentes de la propia agenda temática del ELSJ, incluida la deliberación y voto en Comisión LIBE de los Tratados y Acuerdos internacionales negociados y concluidos por la Comisión Europea por mandato del Consejo, en representación de la personalidad jurídica única de la UE en Derecho internacional (art. 4 TUE), con plena capacidad para obligar de conformidad al Derecho internacional de Tratados (Convenio de Viena de 1969).

Y es que desde la entrada en vigor del TL, el PE tiene la última palabra para que los Tratados concluidos por la UE puedan entrar en vigor; y sin el voto favorable del PE su entrada en vigor no puede tener lugar (art. 218 TFUE). Y esta importante función se ha puesto de manifiesto, dentro de los trabajos de la Comisión LIBE, en dos ocasiones muy sonadas.

La primera consistió en la aprobación del Acuerdo de la UE con los EEUU sobre el Programa de Rastreo de la Financiación del Terrorismo (TFTP, por sus siglas en inglés, aunque periodísticamente conocido como Acuerdo SWIFT) ${ }^{22}$.

Este Acuerdo mejoró el anteriormente negociado por la Comisión Europea y los EEUU con la Administración Bush antes de la entrada en vigor del TL y con carácter previo, pues, a la llegada del Presidente Obama a la Casa Blanca, y que, como se recordará, resultó en su día rechazado por el PE en diciembre de 2009. Tras un nuevo mandato de negociación, el nuevo Acuerdo fue renegociado y concluido, no sin vicisitudes y sorteando muchas dificultades, bajo Pre-

22 Véase, sobre estas cuestiones, Díaz Fernández, A./Revenga Sánchez, M./Lime JiméNEZ, O.: Cooperación Europea en Inteligencia. Aranzadi-Thomsom, 2010. 
sidencia española: el voto favorable del PE (consent) al referido Acuerdo UEEEUU tuvo lugar el 6 de julio de 2010.

La segunda ocasión sobresaliente para el ejercicio de este poder tuvo lugar el 19 de abril de 2012, en la conclusión del Acuerdo entre la UE y los EEUU sobre el llamado Registro de Pasajeros (PNR, Passengers Name Record, por sus siglas en inglés $)^{23}$, objetivo este relanzado tras los llamados «atentados de París» en enero de 2015 (matanza en Charlie Hebdo, preludio de una nueva ola de atentados yihadistas que reactivó la alerta en la UE y sus EE. MM. acerca de las mutaciones de la amenaza terrorista).

Ciertamente, en ambas oportunidades estas iniciativas tenían como telón de fondo la lucha antiterrorista y la criminalidad grave transfronteriza, buscando garantizar mayor seguridad de los ciudadanos europeos contra amenazas compartidas (el terrorismo global y las demás formas relevantes de criminalidad grave transnacional).

En el primer asunto (Acuerdo TFTP/Swift), el objeto del acuerdo era la autorización para transferir desde Europa datos relativos a transferencias bancarias sospechosas de financiar organizaciones o actos terroristas. En el segundo, ofrecer garantías homogéneas en toda la UE a la transmisión al Homeland Security Department (Ministerio del Interior del Gobierno Federal de EEUU) de los datos personales reflejados en la adquisición del billete aéreo e incorporados por las compañías aéreas al embarcar pasajeros con destino a los EEUU.

En lo que nos concierne (dejando de lado, por tanto, la aplicación del llamado «Security Flight Program» por el Home Land Security Department, puesto que éste no tiene marco de negociación bilateral con la UE, tratándose de una aplicación interna de los EEUU aun cuando pueda afectar a vuelos procedentes de la UE e incluso a vuelos con destinos ajenos a los EEUU que puedan sobrevolar espacio aéreo de EEUU), cabe reseñar aquí que el TFTP fue establecido en su día por el Departamento del Tesoro de los EEUU tras los ataques terroristas del 11-S de 2001, encuadrado en la legislación antiterrorista especial bajo la Patriot Act. Desde entonces, el TFTP había venido generando aportaciones significativas en la prevención de atentados y/o de movilización de financiación orientada a la organización de elementos o actos terroristas, lo cual venía siendo estimada como beneficioso tanto para los EEUU como para los EE. MM. de la UE en los objetivos comunes de lucha contra el terrorismo. La hipótesis de un Acuerdo internacional sobre transferencias financieras al Departamento del Tesoro de EEUU se mostraba, en consecuencia, «proporcionada y necesaria» para garantizar la

23 Vid. Brouwer, E.: «Ignoring Dissent and Legality: The EU's proposal to share the personal information of all passengers», CEPS Papers, n. 40, 2011. 
vigencia del propio TFTP y a fin de que continuase generando rendimientos positivos en la estrategia compartida de lucha antiterrorista.

En su Pleno de Estrasburgo de 11 de febrero de 2010, el PE denegó su aprobación (consent) a la celebración del Acuerdo entre la Unión Europea y los Estados Unidos de América sobre «tratamiento y transferencia de datos de mensajería financiera». Se trataba nada menos que la primera votación de aprobación de un Acuerdo internacional tras la entrada en vigor del TL, que ha hecho, precisamente, del PE el titular y emisor de la última y definitiva palabra sobre su entrada en vigor. Haciendo esto, al mismo tiempo, el Parlamento requirió a la Comisión que presentara de inmediato al Consejo una nueva recomendación para un mandato de negociación con vistas a un nuevo Acuerdo UE-EEUU con garantías satisfactorias, y para un período de vigencia de prolongada duración. Subsiguientemente, el 11 de mayo de 2010 el Consejo autorizó formalmente a la Comisión a abrir nuevas negociaciones con los EEUU en nombre de la Unión Europea, con vistas a facilitar «datos de mensajería financiera al Departamento del Tesoro de los EEUU con el fin de prevenir y combatir el terrorismo y su financiación» (Acuerdo TFTP UE-EEUU). La Comisión concluyó las consiguientes negociaciones el 11 de junio, y el 28 del mismo mes se firmó el Acuerdo. Simultáneamente, el Consejo solicitó formalmente la aprobación del PE respecto del proyecto de Decisión del Consejo relativa a la celebración del citado Acuerdo. En este contexto, el PE expresó en reiteradas ocasiones su posición sobre el llamado «mandato de negociación», en una secuencia de resoluciones parlamentarias relevantes. Enumeraba en ellas las mejoras que el nuevo Acuerdo debería incorporar para poder contar con la correspondiente aprobación parlamentaria. En paralelo, además de la mejoras en el Acuerdo, el Consejo y la Comisión adquirieron formalmente el compromiso, con valor jurídicamente vinculante, de establecer un nuevo marco jurídico y técnico para autorizar la «extracción, recolección y tratamiento» de datos de un territorio de la UE.

En síntesis, el Acuerdo definitivo, en combinación con los compromisos jurídicamente vinculantes de la Decisión del Consejo, satisfizo, finalmente, buena parte de las exigencias del PE, tal y como se puso de manifiesto en el voto mayoritariamente favorable logrado en su aprobación. El texto resultante atendió a los requerimientos y preocupaciones legítimas de la representación de los ciudadanos de la UE — el PE — en materia de seguridad y privacidad, y proporciona soluciones jurídicamente vinculantes para los problemas planteados ${ }^{24}$. Pero también, asimismo, lo que no es menos importante, este episodio marcaría una nueva

24 Vid. GuILD, E., y Carrera, S.: «Towards and Internal (In)security Strategy for the EU?», CEPS Papers, n. 35, 2011. 
etapa en la maduración y despliegue de las competencias del propio PE en cuanto tal, asegurando así un control democrático europeo, razonablemente efectivo, de los acuerdos internacionales negociados y suscritos en nombre de la UE.

En cuanto al segundo asunto, en abril de 2012 el PE dio, finalmente, su luz verde al nuevo Acuerdo sobre la Transferencia de datos de pasajeros aéreos entre la UE y EEUU (Acuerdo $P N R$, por sus siglas en inglés). A partir de la votación favorable del PE (consent, art. 218 TFUE) el Tratado establece el marco jurídico que regulará el envío de esta información, y abarca cuestiones variadas como son los periodos de retención, el uso y la protección de los datos y la posibilidad de recurso. El nuevo Acuerdo sustituía al hasta ese mismo momento vigente, que se venía aplicando de forma provisional desde 2007. Negociado por la Comisión Europea y el Gobierno estadounidense a lo largo de 2011, fue finalmente aprobado por una amplia mayoría (409 votos a favor, 226 en contra y 33 abstenciones).

Cabe reseñar, al respecto, que el originario Acuerdo alcanzado en 2007 (conforme a las reglas previas al TL) había sido considerado un «mal acuerdo» en una importante Resolución adoptada por el PE a principios del 2010, por entenderlo basado grosso modo en los criterios que unilateralmente había establecido a priori la parte estadounidense. Debido a las críticas que había suscitado en el PE, la Comisión Europea y su contraparte negociadora en los EE. UU, decidieron renegociar aquel Acuerdo — concluido, en todo caso, con anterioridad a la entrada en vigor del TL - a partir de 2009. La Comisión Europea y los EEUU mostraron disposición a revisar el texto del Acuerdo, modificándolo esencialmente al menos en dos de los tres ámbitos identificados inicialmente como los más problemáticos.

De un lado, el ámbito de aplicación resultó acotado y delimitado. Concretamente, pasan a incluirse ahora el terrorismo y las formas más graves de delincuencia organizada transnacional, y se excluyen los delitos menores, penados con menos de tres años de cárcel. De otro, en cuanto al período de retención, éste se ha reducido para los delitos más serios de 15 a 10 años, manteniéndose en 15 años para los delitos de terrorismo. Transcurridos los primeros 5 años, los datos se instalarán en una base de datos «inactiva» hasta 10 años. Esta base de datos —así llamada, inactiva — estará sometida a controles más exhaustivos, como la restricción del personal autorizado y la exigencia de aprobación de la jerarquía administrativa para acceder a los datos. Posteriormente, se procederá a borrar y eliminar la información que sirva para identificar individualizadamente al pasajero. Los datos relacionados con un caso o una investigación específicos podrán conservarse hasta que se archive la investigación.

Por lo demás, se consideró establecida una «garantía suficiente» de que EEUU utilizará los datos de los pasajeros aéreos con la «finalidad exclusiva de 
prevenir, detectar, investigar y enjuiciar delitos de terrorismo y otros delitos de carácter grave transnacional» que resulten castigados con al menos tres años de cárcel por la legislación estadounidense (purpose limitation clause).

Los pasajeros tendrán acceso a sus datos PNR si así lo solicitan, y podrán requerir a las autoridades de EEUU la corrección o rectificación de su información en caso de que se estime incorrecta o proceda protestar su exactitud o su veracidad. Además, si sus datos no son tratados de conformidad con el acuerdo, podrán presentar un recurso por vía administrativa y judicial en EE. UU.

No puede perderse de vista que esta secuencia de episodios ha venido desplegándose, en sustancial medida a rebufo y so pretexto del preocupante empuje de esa política del miedo que, en los últimos años, ha venido siendo alentada, con una orientación notoriamente antisocial, por la conjunción de dos factores: de un lado, las iniciativas y discursos de Gobiernos cada vez más inclinados a un populismo punitivo que arriesga tintes reaccionarios; de otro, la agonía interminable de esta «Gran Recesión» que, con arranque en la caída de Lehman Brothers en EEUU, ha resultado ser, claramente, a estas alturas, la más profunda y duradera que haya padecido la UE a lo largo de su historia.

En otras palabras, cualquier eventual retroceso en el acervo que conocemos como Schengen — que garantiza la libre circulación de personas en la UE y apunta a una gestión integrada de las fronteras exteriores de la UE- debe ser discutido con máximo celo y conciencia de su valor muy preciado para la ciudadanía europea... si es que no, directamente, desatar la voz de alarma. Porque refleja, en última instancia, la tentación de practicar una vuelta a un nacionalismo rancio cuyas inconsecuencias en la gestión de los flujos migratorios deberían a estas alturas estar del todo superadas. Y porque evidencia, además, que las pulsiones larvadas del antieuropeísmo xenófobo y reaccionario han venido penetrando, desde las nuevas formaciones de extrema derecha y discursos populistas, en la médula espinal de la estrategia política de formaciones que ostentan responsabilidades de Gobierno en buena parte de los EE. MM. La Europa de Schengen - la misma que suprimió el control en las fronteras internas de gran parte de la UE, e incluso ha ido más allá, incorporando a países que no son miembros de la UE — es, a juicio de millones, especialmente los jóvenes, uno de sus más señeros y perceptibles logros. Una consecución que no sólo hay que preservar ahora, frente a los arrecifes de la crisis más severa que haya padecido la UE, sino fortalecer ${ }^{25}$.

25 Vid. Bigo, D.; Carrera, S.; Hayes, B.; Hernanz, N., y Jeandesboz, J.: «Evaluating Current and Forthcoming Proposals on JHA Databases and Smart Borders System at EU external borders», CEPS, 2012. 
Visto lo visto hasta aquí, toca ahora subrayar un importante conjunto de iniciativas señaladas en ámbitos de gran incidencia para el despliegue normativo de las potencialidades del ESLJ en el marco secuencial del Programa de Estocolmo y de su Plan de Acción. Nos referimos, en concreto, al llamado Paquete legislativo de Cooperación Judicial en materia Penal (que incluye la «lisbonización» de las antiguas Decisiones de Europol y Eurojust y la Directiva sobre Sanciones Penales por manejo de información privilegiada y maquinaciones en el mercado (Directive on criminal sanctions for insider Dealing and Market manipulations), junto al no menos importante Paquete sobre la Hoja de Ruta de los Derechos Procesales (Procedural Rights Road Map). Uno y otro elementos jalonan la «lisbonización» de un Espacio Europeo de Justicia Penal, sobre la base jurídica de los artículos clave (82 a 86 TFUE) del TL.

Procede comenzar consignando, usando un criterio cronológico, los derechos de las víctimas ante el proceso penal. Porque, efectivamente, en conexión con los trabajos parlamentarios relativos a los derechos procesales en el ámbito penal, resultan de entrada reseñables los avances producidos en materia de protección de víctimas (ej.: Orden Europea de Protección de Víctimas —iniciativa activada bajo Presidencia española-), en el marco del llamado «Paquete de Víctimas» (Victims Package), éste último activado a iniciativa de la Comisión ya bajo las previsiones del TL.

En concreto, la primera propuesta de Directiva reguladora de la Orden Europea de Protección de Víctimas fue presentada bajo Presidencia española, con el apoyo de otros 11 EE. MM. patrocinadores, en enero del 2010. A partir de ahí, experimentó un recorrido político y parlamentario singularmente complejo y difícil, y ello a pesar del inicial consenso en torno a su objetivo: extender la protección de las víctimas en sus desplazamientos dentro de la Unión Europea.

La iniciativa española fue en su día objeto de críticas por la Comisión Europea, atacando la base jurídica en ese momento escogida por el Consejo al optar por actuar mediante «cooperación reforzada» según lo previsto en el art. 82 TFUE. La argumentación de la Comisión se fundaba en el principio de que, desde la entrada en vigor del TL, los EE. MM. sólo podían —y sólo pueden- adelantar «propuestas» en materia de cooperación judicial en materia penal. Subsiguientemente, la Comisión —a través de quien era entonces su vicepresidenta responsable de Justicia y Derechos Fundamentales, Viviane Reding- formuló por varias vías su rechazo y su protesta tanto contra la «base jurídica» invocada por el Consejo JAI como contra aspectos concretos de la iniciativa adoptada, en cuanto, a su parecer, la originaria propuesta española iba más lejos de lo que resultaba coherente con la «base», tanto en sus ambiciones como en su formulación. 
El funcionamiento de la Orden, tal como aparecía ideada en la propuesta de la Presidencia española, era en realidad bien simple: toda orden de protección, con independencia de la naturaleza del órgano que la emitiese en un Estado miembro, debería ser transformada en un mandato dirigido a la adopción de una «medida equivalente», asegurando el «mismo nivel de protección» en el ordenamiento de otro Estado miembro, siempre y cuando la persona protegida así lo solicitase en caso de «desplazamiento» dentro de la Unión Europea. El objetivo era, y continúa siendo, la prevención del delito, lo que ha de entenderse «independiente» de la «naturaleza del órgano» (penal, civil, administrativo u «ordinario», según su caracterización dentro de cada ordenamiento) que haya de dictar la medida concreta de protección.

Tras largos e intensos debates acerca de la base jurídica y de la naturaleza de las medidas que habrían de entenderse cubiertas en una propuesta de Directiva formulada en este modo y desde la invocación de la base referida en el artículo 82.2 TFUE, las dos ponentes designadas (respectivamente, por la Comisión LIBE y por la Comisión FEMM) acordaron en su día, en búsqueda de un compromiso, reducir el ámbito inicial de aplicación a las medidas de protección de víctimas de delitos, acotando así el campo a las medidas adoptadas por órganos jurisdiccionales penales. Tal decisión fue adoptada desde el compromiso, a su vez, por parte de la Comisión, de presentar un Reglamento que, complementariamente, daría cobertura a la adopción de medidas civiles (y/o administrativas), lo que efectivamente tuvo lugar en mayo de 2011, habiéndose completado a fines de 2012 su entera tramitación legislativa en el PE. La combinación de ambos instrumentos jurídicos permite así asegurar una cobertura adecuada a la práctica totalidad de las medidas de protección aplicadas por los EE. MM. desde la heterogeneidad de sus ordenamientos y de sus instituciones y protección de víctimas.

Partiendo de estos compromisos, la referida Directiva fue aprobada en «segunda lectura» en diciembre de 2010, garantizando a las víctimas de delitos violentos, acoso o trata de seres humanos, el mantenimiento de un mismo «nivel europeo de protección» frente a sus agresores y en sus desplazamientos en toda la UE.

Es importante destacar que la Directiva cubre a todas las víctimas, no solo a las de violencia de género, como muchos criticaron al considerar el campo de aplicación excesivamente reducido. Aunque, estadísticamente (y por causas que aquí no precisan comentario), la mayoría de las medidas de protección beneficien específicamente a las mujeres, la llamada «euroorden de protección» se aplicará, sin embargo, a todo tipo de víctimas — de ambos sexos—, incluidos los niños, que hayan sufrido violencia y cuyo agresor haya sido identificado y sobre el que se haya impuesto una medida de protección. 
La Directiva busca, en resumidas cuentas, proteger a las víctimas, actuales o potenciales, «contra actos delictivos de otra persona que puedan poner en peligro de cualquier modo su vida o su integridad física, psicológica o sexual (...) así como su dignidad o libertad personal».

De modo que si una persona se beneficia de una medida de protección de carácter penal en su país de origen, será este Estado el responsable de solicitar y requerir una orden europea para ampliar la protección al país al que la víctima se desplace. El Estado de origen será así el responsable de emitir la orden europea de protección y reenviarla al país tercero.

Podrá emitirse, en principio, una orden europea cuando el agresor no pueda acceder a los lugares que la víctima frecuenta o cuando exista una orden de alejamiento. Por su parte, el agresor tendrá derecho a recurrir la orden de protección. Sin embargo, al informar al agresor, la autoridad del país de origen tendrá que tener en cuenta el interés de la persona protegida en que no sea desvelada su dirección o cualesquiera otras informaciones de contacto. Como cuestión asimismo de principio, es cierto que esta directiva se aplicará solamente a las medidas judiciales de protección que revistan carácter penal. Sin embargo, debido a las distintas tradiciones jurídicas existentes en los EE. MM., el país al que se traslade la víctima podría imponer medidas de otro tipo (civil o administrativo), siempre que se garantice el mismo nivel de protección. Y debe reseñarse, en fin, cómo, a partir del momento de su aprobación definitiva, los EE. MM. disponen de tres años para transponer en sus ordenamientos, de acuerdo con las condiciones de su configuración (Common Law, Civil Law... etc.) los componentes normativos de esta concreta Directiva.

Visto lo visto, el 13 de diciembre de 2011, el PE aprobó en la llamada «primera lectura» su Resolución legislativa sobre la posición del Consejo con vistas a la adopción de una Directiva del PE y del Consejo sobre la Orden Europea de Protección de Víctimas, publicada finalmente en el Diario Oficial el 21 de diciembre en el 2011.

Esta Orden Europea de Protección de Victimas establece el marco jurídico que va a posibilitar el reconocimiento mutuo de las medidas de protección adoptadas en el ámbito penal. Recuérdese que es, además, el resultado final de la iniciativa de los EE. MM., presentada así al amparo de esta técnica específica de iniciativa estatal en el ELSJ, bajo Presidencia española: concretamente, el resultado de la posterior negociación del PE con el Consejo, que es el que se corresponde con el texto finalmente votado en sesión plenaria en diciembre de 2011. Porque fue sobre esa base, y expresamente en respuesta a la iniciativa adoptada por los EE. MM., sobre la que la Comisión preparó un así denominado «paquete legislativo» de «protección de víctimas» a fin de completar el marco jurídico para su 
protección en el espacio europeo, disponiendo en consecuencia la apertura de un procedimiento legislativo ordinario para la tramitación de este referido «paquete» que fue completado con éxito en 2013.

En cuanto al marco jurídico vinculante de la UE, recuérdese que el artículo 82 (2) del TFUE autoriza al PE y al Consejo a establecer «normas mínimas» para facilitar el reconocimiento mutuo de resoluciones judiciales, así como las condiciones para la cooperación policial y judicial en investigaciones y procedimientos penales con dimensión transfronteriza. Según el aptdo. C) del art. 82 (2), las referidas «normas mínimas» pueden proyectarse también a los derechos de las víctimas de delitos que aparezcan revestidos de una cierta gravedad y alcance transfronterizo.

En su Resolución de 25 de noviembre de 2009 sobre el Programa de Estocolmo (de la que tuve el honor de ser ponente por la Comisión LIBE), el PE formuló un expreso requerimiento en favor de un «marco jurídico global» en disposición de ofrecer la protección más amplia posible a las víctimas de delitos graves transfronterizos (en particular, las víctimas del terrorismo, la delincuencia organizada, la trata de seres humanos y la violencia de género), incluyendo la previsión de una indemnización adecuada.

Así, como respuesta al Programa de Estocolmo y a su posterior Plan de Acción, que estableció en su día la protección de las víctimas como una prioridad, la Comisión publicó (18 de mayo de 2011) un paquete de medidas que incluye, entre otras, las siguientes:

a) Una comunicación sobre el fortalecimiento de los derechos de las víctimas en la UE;

b) Una propuesta de Reglamento sobre el reconocimiento mutuo de las medidas de protección en materia civil;

c) Una propuesta de Directiva que deberá establecer «normas mínimas» europeas sobre el reconocimiento y garantía de derechos, medidas de apoyo y régimen de protección de las víctimas de delitos graves transfronterizos;

Por su parte, siguiendo el mismo método que se siguió en el campo de los derechos procesales de las personas acusadas o sospechosas, el Consejo publicó (10 de junio de 2011) un «Plan de trabajo» para el fortalecimiento de los derechos y la protección de víctimas, singularmente en los procedimientos penales. Al tiempo que subraya la necesidad de un enfoque paso a paso en este campo, la boja de ruta del Consejo abarca las siguientes medidas:

a) La Directiva que deberá sustituir la DM del Consejo 2001/220/JAI, sobre el «Estatuto de las víctimas en los procesos penales»; 
b) Recomendaciones sobre medidas prácticas y mejores prácticas en relación con la Directiva establecida en la medida anteriormente mencionada;

c) El Reglamento sobre reconocimiento mutuo de las medidas de protección en materia civil;

d) La revisión de la Directiva 2004/80, sobre indemnización a las víctimas de delitos;

e) Recomendaciones sobre medidas prácticas y las mejores prácticas para hacer frente a las necesidades específicas de las víctimas.

La Propuesta de Directiva sobre la Protección de las Víctimas del Delito venía así a establecer un nuevo «marco horizontal» para asegurar que todas las víctimas de delitos, independientemente del tipo de delito, puedan beneficiarse de un mismo «nivele europeo de protección» por cuanto hace al derecho de información, al derecho de acceso a los servicios de apoyo a las víctimas, al derecho a ser escuchado, al derecho a interpretación y traducción, al derecho al reembolso de gastos, al derecho a la protección durante el proceso penal. La propuesta incluye, además, una definición amplia de miembros de la familia y sus víctimas, identifica algunas categorías de víctimas vulnerables, y establece un mecanismo para evaluar la vulnerabilidad.

Por último, en este apartado, el referido Paquete de Garantías Procesales en la Investigación de los Delitos autoriza a distinguir tres vertientes en la ruta de desarrollos concretos: Un primer bloque se concentra en los avances relativo al derecho de información, de los imputados y acusados en un proceso penal. Un segundo bloque se ocupa de la aproximación y armonización de los derechos de acceso a la Justicia e interpretación de las actuaciones relevantes en una lengua que resulte comprensible al encausado. Un tercer bloque se concentra en la aproximación en materia de acceso a la asistencia letrada al detenido y al derecho a la defensa en el curso de las actuaciones judiciales (en fase de investigación, o en fase de procedimiento).

En efecto, el PE lleva pidiendo desde hace mucho tiempo una mayor protección de los derechos de las víctimas de los delitos, por un lado, y de los sospechosos o acusados, por otro. Tras el fracaso de la adopción de la DM relativa a determinados derechos procesales en materia penal propuesta por la Comisión en 2004, el Pleno solicitó (en el Informe Pagano, aprobado el 7 de mayo de 2007), un instrumento ambicioso relativo a las garantías procesales en materia penal.

En esta ocasión, la Resolución adoptada por el PE no resultó desatendida. A iniciativa de la Presidencia sueca (segundo semestre de 2009), el Consejo adoptó en noviembre de 2009 un Plan de trabajo para reforzar los derechos procesales 
de los sospechosos o acusados en materia penal que modifica el planteamiento inicial de la Comisión de adoptar un instrumento «horizontal y global» para hacerlo menos ambicioso, pero quizá más realista, con un enfoque por etapas que cubren los siguientes derechos en el escalón europeo:

a) Traducción e interpretación;

b) Información sobre derechos e información sobre los cargos;

c) Asesoramiento jurídico y justicia gratuita;

d) Comunicación con los familiares, el empleador y las autoridades consulares;

e) Salvaguardias y garantías especiales para acusados sospechosos que sean vulnerables;

f) Libro Verde sobre las condiciones de la detención preventiva.

Pues bien, así las cosas, ello quiere decir que este Plan de trabajo (Action Plan) ha pasado ya a conformar, como una parte integrante, el propio Programa de Estocolmo, si bien el mismo deja claro que la lista de objetivos anteriormente reseñados no ha de entenderse exhaustiva.

A partir de ahí las medidas contempladas en este Plan de trabajo se han aplicado parcialmente. La Directiva relativa a los derechos a la interpretación y la traducción en los procesos penales se adoptó el 20 de octubre de 2010, mientras que la tramitación de la relativa al derecho a la información en los procesos penales ha concluido ya su tramitación completa, en espera de su publicación en el Diario Oficial.

La propuesta de Directiva relativa al derecho de acceso a un abogado en los procesos penales y al derecho de comunicación en el momento de la detención fue lanzada por la Comisión el 12 de julio de 2011. Esta iniciativa incluye el derecho de asistencia letrada y asesoramiento jurídico, así como el derecho a la comunicación con los familiares, con el empleador, en su caso, y con las autoridades consulares cuando fuera pertinente.

En concreto, la propuesta de la Comisión estableció, en este ámbito, el principio general de que todo sospechoso o acusado debe tener el derecho de acceso a un abogado lo antes posible y en unas condiciones que le permitan el ejercicio efectivo de su derecho de defensa. También dispone que, en cualquier caso, estos derechos deban garantizarse antes del interrogatorio, antes de la realización de cualquier acto de procedimiento o de prueba, tan pronto como se produzca la privación de libertad.

Pues bien, en conexión con esta Hoja de Ruta de Derechos Procesales en la UE (Procedural Rights) es preciso destacar la importancia del debate suscitado por la 
Propuesta de Directiva de la Orden Europea de Investigación (European Investigation Order/EIO).

Nótese, a este respecto, que, en esta relación de acciones significativas, la base jurídica invocada ha sido la que proporciona el art. 83 TFUE. Lo que, por su parte, explica que el protagonismo de la Comisión LIBE en el desarrollo del ELSJ en materia de progresos en la conversión del PE en legislador penal encuentre un anclaje sólido en el potencial de esta cláusula.

Es precisamente este potencial — cuyo envés evidencia el estadio todavía insatisfactorio de la cooperación judicial transfronteriza en el seno de la UE, si el término de comparación viene fijado, como es el caso, por la internacionalización del crimen - el que hace que la Orden Europea de Investigación (EIO) deba ser entendida como un paso adelante en la buena dirección, orientado a la consolidación de un área penal compartida en el espacio europeo.

Pero, al mismo tiempo, la EIO ejemplifica las tensiones que, en términos de «transferencia de soberanía» comparten estos progresos, máxime en su ponderación con la seguridad y la protección de los derechos fundamentales. Lo que, a su vez, vuelve a acentuar la importancia de un adecuado sistema de control jurisdiccional en garantía de los derechos fundamentales consagrados en la CDFUE con el TL y, consiguientemente, a la formación europea de los operadores jurídicos y, en especial, de los jueces.

Quizá por ello resulta aún más paradójico —y, a mi juicio, problemáticoque se cuestione Schengen (símbolo de la libre circulación de personas en la UE) al tiempo que se reivindica la necesidad de potenciar instrumentos de cooperación policial y judicial más efectivos para asegurar una respuesta proporcionada a los retos derivados de una política común de fronteras y de la libertad de circulación y residencia en la UE de la que, innegablemente, la delincuencia y la criminalidad transfronteriza han obtenido hasta ahora réditos que sobrepasan la capacidad de respuesta de de los EE. MM.

En otras palabras, el equilibrio adecuado entre la libertad de circulación y movimiento de personas y la eficacia en la lucha contra el crimen y contra sus amenazas, ha de ser observado de manera permanente y de acuerdo con los principios de proporcionalidad y de necesariedad (arts. 49 y 51 a 54 CDFUE).

Asimismo, la Orden Europea de Investigación (EIO) epitomiza, mejor que ninguna otra iniciativa hasta la fecha, los principios basales del ELSJ: reconocimiento mutuo de órdenes, mandatos y resoluciones y demás diligencias de investigación, coordinación de investigaciones y garantía de los derechos afectados en el funcionamiento de la Justicia Penal (arts. 82 y 83 TFUE). Se reafirma así el círculo de complementariedad entre el vector del reconocimiento mutuo (expresión de confianza recíproca y de tradiciones y principios comunes) y el 
vector de la aproximación/armonización de la legislación, no sólo en el plano sustantivo sino en el procesal.

Todo ello viene a recordarnos que disponer de una Directiva reguladora de la EIO continúa siendo, a día de hoy, un objetivo relevante en el despliegue del ELSJ de acuerdo con las previsiones del TL por razones evidentes. La recolección de pruebas es crucial en el procedimiento penal. Y es que esta iniciativa incluye la armonización y/o aproximación de las reglas de la investigación del delito, de la identificación de presuntos responsables, y de la sustanciación de las responsabilidades. De lo contrario, en ausencia o en carencia de un instrumento de esta ambición y calado, continuará siendo preciso asegurar que las actuaciones judiciales y expandidas desde un Estado requiriente puedan ser ejecutadas en el Estado requerido, siendo ambos como son EE. MM. de la $\mathrm{UE}^{26}$.

\section{Algunas reflexiones conclusivas}

A la vista de lo expuesto hasta aquí, se puede concluir provisionalmente lo siguiente:

1. El Programa de Estocolmo adoptado en 2009, en paralelo a la propia entrada en vigor del TL, constituyó en su día una causa formidable y prometedora para la legislación penal y para la cooperación judicial en el ámbito penal en la integración europea: se trata nada menos que de la conversión del antiguo acervo del III Pilar en una nueva y genuina política europea sujeta, por tanto, en lo sucesivo, al Derecho europeo. Y toda esa legislación habrá de ser reconvertida — «lisbonizada», en la jerga- de acuerdo con el procedimiento legislativo ordinario que hace del PE, por primera vez en la historia de la integración supranacional, legislador penal. El PE informó en su momento el Programa de Estocolmo. Y debería adoptar también una resolución para su evaluación, en esta fase transitoria hacia su ejecución marcada por el final de la legislatura 2009-2014.

2. El TL representa, hasta la fecha, el escenario más potente y promisorio en toda la historia de la integración supranacional europea para el despliegue de las potencialidades del ELSJ. Pero lo representa también para la proyección de la CDFUE y de los principios de seguridad jurídica, de «proporcionalidad»y de «necesidad» y/o «subsidiariedad» en la articu-

26 Véase SAYERS, D.: «The European Investigation Order: Travelling without a Roadmap», CEPS Papers, n. 42, 2011. 
lación y aplicación de la legalidad penal. Este nuevo despliegue de la ambición europea en la «aproximación» y/o «armonización» de la legislación penal en el escalón europeo emerge, con mayor claridad que nunca antes, como una nueva esfera de legislación compactada - cooperativa e interactiva- entre los legisladores de la UE y los EE. MM.

3. Los principios institucionales del ELSJ establecidos en el Título V del TFUE (arts. 67 a 89) conciernen tanto al Derecho Penal sustantivo como al Derecho Procesal, en una combinación de fijación de estándares 0 «reglas comunes europeas» y márgenes de maniobra atribuidos a los legisladores estatales de los EE. MM.

4. Los desarrollos futuros de los principios de primacía, eficacia directa, interpretación uniforme, seguridad jurídica y garantía jurisdiccional de los derechos de la ciudadanía, en el marco de las legislaciones internas en los EEMM y de las tradiciones constitucionales comunes a todos ellos, requerirán un ejercicio intensivo de clarificación judicial por vía interpretativa, tanto por parte del TJ como de los poderes judiciales de los EE. MM. Ello acentuará, sin duda, la indeclinable importancia de la formación especializada en Derecho europeo así como de las técnicas de cooperación jurídica transfronteriza entre los operadores y profesionales del Derecho en los EE. MM. Lo que, en última instancia, sin duda comporta y exige poner particular énfasis en la formación judicial en el Derecho europeo.

\section{EL PARLAMENTO EUROPEO COMO LEGISLADOR EN MATERIA PROCESAL PENAL Y EL DERECHO A LA DEFENSA EN EL PROCESO PENAL}

\section{Los derechos de la defensa en el Tratado de Lisboa y la Carta de Derechos Fundamentales de la Unión Europea}

Partimos también aquí de la premisa asumida en el apartado anterior: el carácter simbólico y expresivo del TL jalona la dimensión política y la ambición constitucional de la UE. Y es por ello que resulta hoy pacífico aceptar que el decurso de la integración europea describe un itinerario protoconstitucional.

También esta historia ha sido contada innumerables veces.

Partiendo de la adopción de los primeros Tratados Constitutivos de las entonces llamadas «Comunidades Europeas» (Tratado de la CECA, de 18 de abril de 1951, y Tratados de la CEEA-EURATOM y de la CEE, de 27 de marzo 
de 1957), se procedió tempranamente — merced al exitoso completamiento del «mercado común» y a la realización de las «cuatro libertades» constitutivas del mismo - a la apertura de un ciclo de profundización y ensanchamiento europeo, de gran contenido político, caracterizado por el arrojo y la visión de los líderes del momento (años 80 y primera mitad de los 90 del pasado siglo xx).

Se sucedieron así los jalones de esta segunda etapa, referenciada a menudo como la de una irrepetible «galopada» europea: del Acta Única Europea (1986) se trascendió a la adopción del relevante Tratado de la Unión Europea (en adelante TUE, más conocido como Maastricht, 1992).

Entre otras innovaciones históricas e institucionales, el TUE inaugura una novedosa «estructura de tres pilares»: un primer pilar propiamente comunitario, un segundo pilar intergubernamental en materia de política exterior, seguridad y defensa, y un tercer pilar intergubernamental para asuntos de Justicia e Interior, estos dos últimos pilares dotados de sus estructuras, procedimientos de decisión y fuentes normativas propias.

Su entrada en vigor se vio, no obstante, prontamente subseguida por sucesivas revisiones y refundiciones, en su momento operadas por el Tratado de Ámsterdam (1997) y por el Tratado de Niza (2000).

La rápida constatación de las limitaciones del Tratado de Niza (cuyo abstruso nivel de complejidad y sofisticación se explica por la trabazón inextricable de las fuentes entonces disponibles) determinó la inmediata —en la práctica, instantánea- apertura de un ambicioso ciclo constituyente, virtual tercera etapa de la construcción europea.

Se sucedió así la original convocatoria de una Convención constitucional europea que desplegó su actividad en los años 2000-2004, y de la que resultaron, como eslabones sucesivos de una cadena, los textos de la llamada «Constitución Europea», luego sucedida por un «Tratado Constitucional» que habría de ser sometido a sucesivos procesos de ratificación por los EE. MM. (incluyendo la celebración de referendos nacionales en España, con resultado afirmativo, y en Francia y en Países Bajos, con resultado negativo)... y su desatascamiento y desembocadura en el así llamado Tratado de Lisboa (por resultar desbloqueado en presidencia portuguesa, diciembre de 2007).

El TL incluye, como piezas imbricadas entre sí, una versión refundida del TUE en 55 artículos, una versión refundida del Tratado de Funcionamiento de la Unión Europea (en adelante TFUE), en 358 artículos, y la Carta de Derechos Fundamentales de la UE (por fin un genuino Bill of Rights europeo, en adelante CDFUE, con 54 artículos), además de una treintena de Protocolos anexos y otras tantas Declaraciones solemnes. Su entrada en vigor tuvo lugar finalmente, tras muchas vicisitudes (objeciones polaca y checa a su ratificación, en el tracto final), 
el 1 de diciembre de 2009. Y precisamente por ello, por haberse sobrepuesto a tantas dificultades, el TL refleja como nunca antes la dimensión política y la ambición constitucional europea. Así lo exhiben, al menos, los siguientes rasgos:

a) Consagra valores fundacionales y constitutivos de la UE (art. 2 TUE) y ordena la adhesión de la UE al CEDH (y, por consiguiente, a la doctrina elaborada por el Tribunal Europeo de Derechos Humanos (en adelante TEDH) de Estrasburgo, art. 6 TUE); b) Proclama valores fundamentales (art. 2 TUE) y propugna objetivos permanentes de la UE (solidaridad, cohesión, integración territorial, art. 3 TUE); c) Crea figuras nuevas para potenciar la identidad política de la UE (el Presidente permanente del Consejo, la Comisión legitimada y responsable ante el PE, el Alto Representante para la Política Exterior, que es vicepresidente de la Comisión y Presidente del Consejo de Asuntos Exteriores de la UE); d) Establece un nuevo conjunto de herramientas para la gobernanza de la moneda única y de la unión monetaria, en la que sobresale el Banco Central Europeo como nueva institución, además de disponer lo imprescindible para acompañarla de un ciclo de gobierno económico europeo; e) Mandata una política exterior común, con el propósito de hacer de la UE un actor globalmente relevante, disponiendo para ello de un Servicio Europeo de Acción Exterior y una diplomacia conjunta; f) Incorpora un Espacio de Libertad, Seguridad y Justicia (en adelante ELSJ, arts. 67 a 89 TFUE) como un dominio de política interior de la UE (ciudadanía, extranjería, asilo, refugio, gestión común de fronteras exteriores de la UE, política común de inmigración, solidaridad interior, cooperación judicial civil, cooperación policial y judicial en materia penal, lucha contra la criminalidad organizada transfronteriza y grave, Fiscalía europea, estrategia de seguridad interior, cooperación antiterrorista; con un programa quinquenal de actuaciones para su desarrollo: el Programa de Estocolmo adoptado en 2009 bajo la presidencia sueca del Consejo..., lisbonizando, en suma, todo el acervo del anterior III Pilar en materia de Justicia e Interior).

Procede aquí, nuevamente, refrescar la necesaria y particular referencia al Programa de Estocolmo (2009-2014), complementado por su correlativo Plan de Acción adoptado durante la presidencia española de la UE (primer semestre de 2010) y el despliegue del ELSJ (arts. 67 a 89 TFUE).

Llegados a este punto es preciso subrayar que el ELSJ pasa a ser, tras el TL, una política comunitaria sujeta (con excepciones y modalidades concretas de aplicación) al procedimiento legislativo común. Estamos hablando, por tanto de una nueva política, genuinamente europea, que trasciende por lo tanto su preliminar estadio de cooperación reforzada intergubernamental en el marco del anterior III Pilar. 
Así lo explican, en efecto, los mandatos dirigidos a llenar de contenido el recién incorporado capítulo de derechos fundamentales (ratificación del CEDH), así como a completar los grandes objetivos legislativos del Programa de Estocolmo. Entre ellos: el llamado Paquete de Inmigración (Single Permit, Seasonal Workers, Intracorporate Transfers); el Paquete de Asilo (Eurodac, Dublin II, Reglas de Identificación y Procedimiento; Condiciones de Recepción); la lisbonización de las Agencias europeas que operan en este ámbito (Frontex, Eurojust, Europol, EASO, EDPS, FRA...); la promoción de un hoy todavía embrionario Derecho Europeo de Contratos, de un también incipiente Proceso Penal europeo, y de instrumentos europeos de Protección de Víctimas (de carácter administrativo, penal y civil), así como de la Estrategia de Seguridad Interior en la UE (Terrorismo, Mafia y Crimen Organizado, Ciberdelincuencia, Pornografía Infantil, Iniciativas Antidroga).

Todos estos elementos componen conjuntamente un cuadro de contenidos ciertamente relevante, y que, a mi juicio, es expresivo como ningún otro de la dimensión política y de la ambición constitucional de la UE.

Pero estos expedientes son, también, una expresión de la expansión de los dominios materiales de la acción y la influencia del PE, legislador ahora ordinario, en codecisión con el Consejo en todas estas materias anteriormente reservadas a las «decisiones marco» adoptadas por cooperación reforzada en el III Pilar (intergubernamental, es decir, no comunitario).

Ello quiere decir que la extensión de los lindes del PE acarrea, con mayor claridad y contundencia que nunca antes, la propia expansión de su método decisional distintivo de su complejidad y vocación integradora de alcance supranacional: la regla dominante ahora es, efectivamente, el procedimiento legislativo ordinario (en el que el Parlamento codecide con el Consejo como legislador ordinario de la UE), bajo el control jurisdiccional del Tribunal de Justicia (-integrado ahora por el TJUE, por el Tribunal General —antiguo Tribunal de Primera Instancia-, y por los Tribunales especializados que sean establecidos por la legislación europea, de los que ya está en funcionamiento el Tribunal de la Función Pública comunitaria).

Como es conocido, este cuadro de protección de derechos, reforzado por el TL, incluye no solamente la relevante incorporación de la CDFUE, sino también, ahí es nada, la incorporación al acervo europeo del Convenio Europeo de Derechos Humanos (en adelante CEDH) de 4 de noviembre de 1950 [que es un Convenio obediente al sistema jurídico propio del Consejo de Europa, instituido en 1948, y que, con 47 Estados miembros (en adelante EE. MM.), describe un círculo más amplio, aunque concéntrico, con el sistema jurídico de la UE]. 
Lo que comporta — ahí es nada — un mandato de diálogo jurisprudencial del TJ con el TEDH. Una conversación que viene así a sumarse al diálogo ya operativo con las Cortes Constitucionales y Tribunales Supremos de los EE. MM.

Pero es que, además de ello, el TL impacta también sobre el conjunto de los valores democráticos y del compromiso común con la regla del derecho (rule of Law, imperio de la Ley, principio de legalidad en el marco de las «tradiciones constitucionales comunes», art. 2 TUE) y las instituciones que expresan la democracia representativa y sus relaciones recíprocas con las restantes instituciones europeas.

Porque, efectivamente, de todas las instituciones de la arquitectura compleja de la UE, única e irrepetible en su naturaleza y su escala (como no puede ser de otra manera, porque siempre es así cuando se acomete el análisis constitucional con el detalle específico del rigor y de la precisión obligada), si hay una que emerja reforzada con nitidez indiscutible, esa es el Parlamento Europeo (en adelante PE).

Es un hecho subrayado con insistencia que el PE sale muy fortalecido del TL.

Y lo hace en todos los ámbitos. Lo hace como órgano legislador, y en competencias extensivas, muy ampliadas respecto de sus anteriores dominios. Y lo hace como órgano político distinguido por ser el único órgano europeo legitimado directamente por el voto popular.

Las páginas que siguen se proponen examinar, de manera más concreta, el derecho al abogado y a la asistencia letrada, y su relevancia en el marco de la armonización de los principios procesales en el Derecho Europeo: esto es, de la armonización/aproximación del Derecho Penal y del Derecho Procesal Penal de los EE. MM. de la UE. Requieren especial énfasis los presupuestos procesales de la cooperación judicial en materia penal: la confianza mutua y el reconocimiento mutuo entre los ordenamientos de los EE. MM., cruciales para el refuerzo de la cooperación policial y judicial penal. Y los objetivos comunes asegurados por medio de una constelación de agencias europeas: OLAF/Europol/CEPOL/Eurojust/Red Judicial Europea, y la futura institución de la Fiscalía Europea (EPPO).

El obstáculo primordial que debe ser superado a la hora de enhebrar los mimbres para un Espacio Europeo de Justicia Penal reside en la identificación de aquellos principios estructurales de carácter procesal que permiten vislumbrar una «cultura común europea» al tiempo que «tradiciones constitucionales comunes» (art. 2 TUE) desde la perspectiva del Derecho comparado.

Como se ha resaltado, persisten a día de hoy importante divergencias (como también analogías) en los principios procesales, un problema que es sustrato de la llamada DM sobre Derechos Procesales de 2003 y de la Hoja de Ruta de 2011 en la materia. 
La legitimación de la intervención legislativa de la UE depende en buena medida del correspondiente test nacional de subsidiariedad, sin que resulte despreciable la conciencia (y la demanda) ciudadana de protección de derechos procesales ante los tribunales de Justicia (incluidos los escalones supranacionales que corresponden al TEDH y al TJ) y la conciencia ciudadana de la ciudadanía europea.

Desde esta óptica, intensamente condicionada por la metodología del Derecho comparado, los derechos de la defensa que aparecen como objeto de la garantía más intensa incluyen la presunción de inocencia (objeto, como se verá, de una procedimiento legislativo europeo); el derecho a la asistencia jurídica y a la defensa letrada; el acceso a la información de los cargos en su contra; el derecho a permanecer en silencio o a no declarar contra sí mismo ( «the right to remain silent», y, en algunos ordenamientos, «the right to lie», el derecho a mentir); el derecho a un juicio justo; el principio de legalidad penal; la seguridad jurídica; la no retroactividad de la regla menos favorable al acusado o al reo: el derecho a la prueba pertinente en la defensa; a la igualdad de armas; a la carga de la prueba («burden of proof») y las pruebas de descargo; el respeto a la intimidad personal y familiar en la investigación; la regla del non bis in idem; a la motivación de la resolución judicial; a la imparcialidad del órgano enjuiciador; al juez predeterminado por la ley («the right to lawful judge»); a estar presente en el acto de enjuiciamiento; a una justicia tiempo razonable ( «ithin reasonable delay»); $y$, con grandes variaciones, a determinadas modalidades de enjuiciamiento por jurados (Jury Trial).

El derecho a un juicio público con todas las garantías ha resultado consagrado en la jurisprudencia del TEDH (Caso Engels) y en la CDFUE. En cambio, las variaciones en las condiciones temporales y materiales de la detención y la privación de la libertad resultan de amplísimo espectro.

Lo mismo cabe predicar de los heterogéneos niveles de protección de las víctimas (sea en la fase real, sea a través de declaraciones por escrito) y de concreción de la técnica del «derecho a ser oído» en la fase de investigación.

La brecha de las divergencias en perspectiva comparada es asimismo muy amplia en lo concerniente a las reglas para la inadmisión de pruebas ilícitamente obtenidas o con violación de los derechos fundamentales (la «fruta del árbol prohibido»): en algunos EE. MM., el margen de discreción judicial para la exclusión de las pruebas ilícitas es amplio; en otros, se excluyen todas las potencialmente lesivas de derechos fundamentales. Es éste también un obstáculo que debe ser considerado con particular atención. 


\section{El Programa de Estocolmo y los Derechos procesales en la Unión Europea}

Tal como se ha advertido anteriormente, la adopción del Programa de Estocolmo para el desarrollo del ELSJ tuvo lugar durante la Presidencia rotatoria sueca (segundo semestre de 2009), en exacta coincidencia con el desbloqueo del impasse que retuvo durante dos años (2007-2009) la entrada en vigor del TL. Este Programa de Estocolmo supuso la continuación de sus predecesores Programa de Tampere (Presidencia finlandesa, 1999) y Programa de la Haya (Presidencia holandesa, 2004), caracterizados por su carácter quinquenal, pero también, y sobre todo, por su factura y naturaleza intergubernamental.

En efecto, la entrada en vigor del TL redefinió íntegramente las reglas del juego en el despliegue del ELSJ. En la medida en que el PE pasa a ser, finalmente, legislador, en pie de igualdad con el Consejo, en materia de Justicia, Interior y Derechos Fundamentales (en desarrollo de la CDFUE) desde la vigencia del TL, el PE ha pasado a ser actor principal y decisivo tanto en la determinación de los contenidos y objetivos del Programa como en su implementación, requerida de acción legislativa en el escalón europeo.

En este nuevo contexto, la Comisión Barroso II (2009-2014) asumió el compromiso de promover, desde el área de responsabilidad de la Vicepresidenta Viviane Reding (Comisaria de Justicia y Derechos Fundamentales) un Plan de Trabajo para la armonización de los derechos procesales en la UE (Procedural Rights Road Map).

De este Plan de Trabajo resultaría la adopción por parte de la Comisión de siete iniciativas legislativas interconectadas entre sí, en dos fases sucesivas. A lo largo de la Legislatura 2009-2014 del PE, el primer paquete comprendió tres propuestas de Directivas:

a) Directiva sobre el derecho de acceso a la información sobre la acusación en los procesos penales;

b) Directiva sobre el acceso a interpretación y traducción en los procesos penales;

c) Directiva sobre el acceso a un abogado, a la asistencia letrada y el derecho a la defensa en los procesos penales.

Este primer paquete fue tramitado y completado durante la Legislatura 2009-2014. En la Legislatura 2014-2019, la nueva Comisión Juncker revalidó su compromiso de continuación del Paquete de Armonización de Derechos Pro- 
cesales en la UE. En concreto, ha asumido en su Plan de Trabajo la promoción de otras cuatro iniciativas legislativas:

a) Directiva sobre la garantía del derecho a la presunción de inocencia y a un juicio justo en los procesos penales de la UE;

b) Directiva sobre las garantía procesales de los menores sospechosos o inculpados;

c) Directiva sobre el derecho a la asistencia jurídica (ante la insuficiencia de recursos suficientes para litigar) en procesos penales en la UE;

d) Directiva sobre el derecho a asegurar la presencia del acusado en los procesos penales en la UE.

3. El Plan de Trabajo para el fortalecimiento de los derechos procesales de las personas sospechosas y del acusado en el proceso penal en la Unión Europea

Ante todo, la distribución de competencias y garantías procesales entre instituciones investigadoras exhibe también grandes divergencias en perspectiva comparada. Así, en lo concerniente a la confiscación y congelación de activos; a la videovigilancia; a las pruebas de $\mathrm{ADN}$; a las intervenciones de las comunicaciones; a la duración máxima de la detención preventiva y la retención policial.

Con vistas a la prefiguración de una Fiscalía Europea que beba de todas las fuentes del Derecho comparado de los EE. MM., es especialmente importante delinear la diferencia entre los ordenamientos que incluyen una fiscalía jerarquizada, orientada a asegurar la «unidad de actuación» (España, Austria, Bélgica, Alemania, Suecia, Luxemburgo...) respecto de aquellos en que la investigación disfruta de mayores márgenes de independencia funcional (Italia, Irlanda, Malta, Reino Unido...).

En todos los casos, en cambio, aparece como un principio común la posibilidad de revisar judicialmente las actuaciones investigadoras de la policía o la fiscalía. Asimismo, se observan reglas generales para asegurar el derecho a solicitar/requerir «diligencias» adicionales (investigative measures), aun cuando no revistan garantía constitucional expresa.

Las divergencias son también notables en la caracterización del derecho a proponer pruebas para la defensa (por vía oral, documental o por videoconferencia) y para la participación de las víctimas en el proceso.

La regla non bis in idem aparece consagrado en la práctica totalidad de las constituciones de los EE. MM., así como en la CDFUE (art. 48).

Con ello parece obvio que los principios básicos de la «confianza mutua»y «reconocimiento recíproco» de actuaciones en el ámbito de la Justicia Penal 
entre los EE. MM. arraiga en «valores comunes», «principios y tradiciones constitucionales» compartidos... pero también en los obstáculos impuestos por las imperfecciones o faltas de correspondencia con la tipificación (double incrimination), así como en la naturaleza y duración de las penas y sanciones a aplicar.

Lo que conduce al desafío de la definición de los llamados «maximum y minimum sanctions», y al no menor reto de aproximar las condiciones de la detención y de la privación de libertad en la UE (malos tratos o brutalidad policial o penitenciaria; pesquisas o intervenciones físicas; condiciones de seguridad personal o saturación penitenciaria; sanciones de aislamiento; salubridad en las cárceles,...).

La jurisprudencia del TEDH es, en este último respecto, singularmente demoledora. Prácticamente ningún Estado miembro del Consejo de Europa está libre de condenas señeras con responsabilidad por violación de derechos consagrados en el $\mathrm{CEDH}$ en este ámbito, sobresaliendo casos de gran impacto en Italia, Grecia, Polonia, Rumanía... entre otros reseñables.

Atendiendo a estas demandas, por Resolución del Consejo de 30 de noviembre de 2009 —en coincidencia con la adopción del Programa de Estocolmo en la Presidencia sueca de la UE_-, se adoptó el Plan de Trabajo para reforzar los derechos procesales de sospechosos o acusados en los procesos penales celebrados en la UE (Procedural Rights Road Map), diseñado por la Comisión.

Por medio de este Plan, los Jefes de Estado y de Gobierno se comprometieron a ejecutar las acciones a escala europea que resultaran pertinentes para adoptar medidas legislativas orientada al refuerzo de los derechos procesales del sospechoso y del acusado en los procesos penales, asegurando un equilibrio entre eficacia de los procedimientos y el fortalecimiento de las garantías y del Estado de Derecho en toda la UE.

Para ello, la UE invoca los estándares del CEDH y la jurisprudencia del TEDH (art. 6.2 TUE), el principio de confianza y reconocimiento mutuo y los Derechos Fundamentales de la CDFUE especialmente incidentes en los procesos penales (arts. 47 a 50) que resultan de rigurosa vinculación a la hora de legislar sobre las medidas propuestas. Este «Paquete de Derechos Procesales» le compromete a abordar:

a) el derecho a la traducción y la interpretación en los procesos penales;

b) el derecho a ser informado sobre los propios derechos y sobre los cargos y acusaciones en su contra;

c) el derecho al asesoramiento legal y a la asistencia jurídica; 
d) el derecho de toda persona detenida a comunicarse con miembros de la familia, con su empleador/a y con las autoridades consulares del país del que se es ciudadano;

e) un paquete normativo de garantías específicas para personas sospechosas o acusados que presenten situaciones de especial vulnerabilidad (los menores).

Como complemento de la estrategia conjunta a desplegar, los Estados se comprometen igualmente a garantizar la asistencia jurídica gratuita (legal aid) cuando así lo requieran las condiciones económicas de la persona que acredita insuficiencia de recursos.

Recuérdese que el Programa de Estocolmo se propuso desplegar en su periodo quinquenal 2009-2014 los objetivos encartados en el Título V del TFUE (arts. 67-89) relativo al ELSJ: «desarrollar una Europa de la ciudadanía; proteger sus derechos; asegurar y reforzar el imperio de la Ley y el acceso de la Justicia; y acometer el principio de la «Europa que protege» mediante la aprobación de una Estrategia de Seguridad Interior (art. 71 TFUE).

El Consejo, con la adopción de esta importante Resolución de 30 de noviembre de 2009, invita a la Comisión a adoptar las propuestas previstas en el Plan de Trabajo.

Pues bien, la Comisión comprometió un Programa de Trabajo, bajo la responsabilidad de la Vicepresidente Viviane Reding, con los siguientes elementos componentes para el periodo 2009-2013:

a) Directiva (2010/64) del derecho a interpretación y traducción en los procesos penales;

b) Libro Verde sobre la aplicación de la legislación penal de la UE en el ámbito de la detención de personas (14 junio 2011);

c) Directiva 2012/13, 22 de mayo de 2012, sobre el derecho a la información sobre sus derechos y sobre la acusación en su contra en los procesos penales (con especial impacto sobre la Orden de Detención Europea, establecida en la Decisión Marco del Consejo de 13 de junio de 2002).

Para la actual Legislatura 2014-2019, la Comisión ha comprometido, bajo la responsabilidad de la Comisaria Vera Jourova (Justicia y Protección de los Consumidores), el siguiente conjunto de iniciativas:

a) Directiva sobre el derecho a la presunción de inocencia y sobre el derecho a estar presente en los procesos penales;

b) Protección de los derechos procesales de los menores sospechosos o acusados en los procesos penales; 
c) Asistencia jurídica gratuita (Provisional legal aid), y su especial impacto sobre la Orden de Detención Europea (Decisión Marco de 2002).

Enumeremos los materiales componentes del Plan de Trabajo de la Comisión.

a) El Libro Verde de la Comisión sobre garantías procesales para sospechosos e inculpados en procesos penales en la UE;

b) La propuesta de Decisión Marco del Consejo sobre derechos procesales en procesos penales en la UE;

c) El Plan de Trabajo del refuerzo de derechos procesales de sospechosos e inculpados en la UE (Roadmap for Strengthening Procedural Rights);

d) Balance legislativo de la Legislatura 2009-2014.

En perspectiva comparada, la garantía de la defensa letrada exhibe variaciones vinculadas a la vulnerabilidad del imputado (por ejemplo, los menores); a la gravedad de los delitos; a la admisibilidad de los juicios «in absentia» (contumacia, rebeldía....), y por supuesto a las reglas de cobertura pública de la asistencia jurídica (legal aid) ante la insuficiencia de recursos para litigar.

En un amplio número de EE. MM. la asistencia jurídica «de oficio» (paid on legal aid) se apoya en un examen objetivo de los recursos y medios económicos del justiciable (España, Austria, Bélgica, Grecia, Francia, Portugal, Reino Unido...). En otros casos contados, se ponderan otros elementos (Bulgaria, Rumania, Suecia), y, excepcionalmente, algunos contados EE. MM. contemplan la devolución de la ayuda en caso de una sentencia condenatoria final (Dinamarca, por ejemplo).

La cultura comparada de la ciudadanía europea sustenta la expectativa de asistencia letrada pagada con recursos públicos en caso de insuficiencia. De ahí que la Hoja de Ruta del Derecho Procesal puesta en marcha en la legislatura 2009-2014 haya incluido este objetivo entre los principales de la aproximación y de la configuración del Espacio Europeo de Justicia Penal.

Además de todo ello, el tratamiento jurídico de la responsabilidad penal de los menores es, sin lugar a dudas, uno de los asuntos que más controversia suscita a la hora de asentar la base de un Espacio Europeo de Justicia Penal. Para empezar, la edad mínima en la que resulte exigible algún tipo de responsabilidad: desde los 9 años de Malta, los 10 de Irlanda y Reino Unido, los 12 de Países Bajos, los 13 de Francia, Grecia y Polonia, los 14 de casi todos los demás (incluido España), los 15 de Dinamarca, Chequia, Finlandia, Suecia, y los 16 de Luxemburgo, Bélgica, Portugal y Lituania.

De modo que, en el conjunto de los EE. MM., los derechos procesales de los menores aparecen de un modo u otro especialmente reforzados. Asistencia letra- 
da, derecho a ser oído, implicación de instituciones de asistencia social y protección familiar, así como las más restrictivas prácticas de investigación.

También varían los períodos máximos de privación de libertad para los menores: desde los 2 años de Letonia hasta los 20 de Austria y Suecia, el período mayoritario está entre los 10 y los 12 años seguidos de tratamiento de reeducacion y reinserción social.

Con estos antecedentes en mente, el horizonte del Plan de trabajo legislativo en la Legislatura 2014-2019 apunta al fortalecimiento de las bases comunes de la Justicia Penal en la UE.

Recuérdese que el Derecho de las personas sospechosas y acusados a tener un juicio justo es un derecho fundamental en el art. 47 del CDFUE. En su momento, la propuesta inicial de la Decisión Marco del Consejo relativa a las garantías procesales en los procedimientos penales, presentado por la Comisión en 2004, quedó bloqueada hasta la adopción por el Consejo del Plan de Trabajo de 30 de noviembre de 2009. De acuerdo con este plan, la Comisión determinó seis ámbitos determinados por la adopción de iniciativas: a) Traducción e interpretación; b) Información sobre derechos y cargos y acusaciones en su contra; c) Asesoramiento y asistencia jurídica gratuita; de derecho a comunicarse con familiares, empleador y autoridades consulares; e) Garantías especiales para personas vulnerables; f) Libro verde sobre la prisión provisional.

Pues bien, como se ha señalado, en octubre de 2010, Parlamento y Consejo adoptaron la Directiva de traducción e interpretación en procesos penales (2010/64). En mayo de 2012, la Directiva 2012/13 sobre el derecho a la información en los procesos penales. En octubre de 2013 la Directiva de 2013/48 sobre asistencia letrada y derecho a la comunicación. En junio 2011, el Libro Verde sobre detención preventiva y prisión provisional, seguido de la resolución del PE adoptada en diciembre de 2011. El 27 de noviembre de 2013, la Comisión planteó al complemento de su hoja de ruta (Procedural Rights Road Map) con el anuncio de iniciativas sobre la presunción de inocencia, las garantías procesales y la asistencia jurídica gratuita.

La Hoja de Ruta del Derecho Procesal de la UE de 2009, delinea los rasgos comunes del desarrollo de un Espacio Europeo de Justicia Penal desde la perspectiva del derecho a la defensa. Su sustrato común jurídico comparado reviste la mayor importancia a la hora de entender el alcance y envergadura de los objetivos a cambiar. De un lado, una evaluación objetivada e inteligente de los pasos y medidas a adoptar y de sus respectivos costes político-legislativos en los EE. MM.. En segundo lugar, procede abordar una prognosis de los derechos procesales implicados en nivel de mayor intensidad. Teniendo en mente, ante todo, que de lo que estamos hablando es de diferenciar el escalón europeo de 
protección, como genuino y autónomo, respecto de los nacionales. Que lo mismo cabe predicar de las de medidas de investigación y de las reglas de exclusión de pruebas y de doble incriminación (incluido el principio europeo de prohibición de no bis in idem.

Por otro lado, también en septiembre de 2011, la Comisión Europea publicó su Comunicación: «Hacia una Política de Derecho Penal en la UE: garantizando la aplicación efectiva de las políticas de la UE mediante el Derecho Penal». A través de esta estrategia se trata de establecer un conjunto de normas mínimas de Derecho Penal en toda la UE contra la delincuencia y la criminalidad, garantizando la homogeneidad, cohesión y coherencia de la legislación penal de los EE. MM. en cuanto a los objetivos compartidos.

Vemos, pues, cómo en el nuevo marco estructurado por el TL —codecisión/ procedimiento legislativo ordinario para el despliegue del ELSJ (con la excepción del art. 86 sobre la Fiscalía Europea) — y con la desaparición de la antigua estructura de «Pilares», el PE adquiere mayor protagonismo legislativo que nunca, vinculado por los principios establecidos en la CDFUE, revestida, como se ha advertido, del «mismo valor jurídico que los Tratados.

Además de su tarea legislativa, el PE ha adoptado numerosas resoluciones sobre cooperación judicial en materia penal: conflicto de jurisdicción; medidas de vigilancia sustitutivas de la prisión provisional; exhorto europeo de obtención y transmisión de pruebas; Eurojust, Red Judicial Europea; resoluciones en ausencia del acusado; criminalidad medioambiental; terrorismo; trata de seres humanos; explotación sexual de niños y pornografía infantil; apoyo y protección a las víctimas de los delitos.

En mayo de 2012, el PE adoptó su Resolución (Informe de Propia Iniciativa, Ponente De Jong) sobre un «Enfoque global sobre Derecho Penal», desarrollando criterios para asegurar la cohesión y la calidad del Derecho Penal en los EE. MM. y en la UE.

A lo largo de 2014, el PE aprobó en primera lectura las siguientes Directivas: Directiva sobre el Embargo Preventivo y Decomiso de los Productos de la Criminalidad; Directiva sobre operaciones con información privilegiada y manipulación del mercado; Directiva contra el Fraude que afecta a los interés financieros de la UE mediante el Derecho Penal (Directiva PIF); Directivas sobre la Protección del euro frente a la falsificación; Directiva sobre Prevención del uso del sistema financiero para fines de blanqueo de dinero y financiación del terrorismo. En marzo de 2014, el PE votó una Resolución (Informe Intermedio) sobre la Propuesta de Reglamento del Consejo sobre la creación de la Fiscalía Europea. 
Complementariamente a todo ello, el PE participa en la evaluación y supervisión periódica del ELSJ (art. 70 TFUE) en diálogo y cooperación con los Parlamentos Nacionales (Conferencias Interparlamentarias semestrales en el ámbito del ELSJ). La misma previsión se contempla para la evaluación de las actividades del Eurojust (art. 85 TFUE).

\section{El derecho al Abogado, a la defensa letrada y a la asistencia jurídica}

1. El derecho al abogado y a la defensa letrada y «contenido esencial» de los derechos procesales en el ELSJ. Incluye los siguientes derechos:

a. Abogado, defensa letrada y derecho a conocer en una lengua asequible la acusación y las actuaciones policiales y judiciales en su contra: derecho a la interpretación y a la traducción;

b. Abogado, defensa letrada y derecho a la información sobre los «cargos» (imputaciones y acusaciones) en su contra, derecho de acceso a los materiales del expediente y derecho a ser informado sobre el número máximo de horas que una persona sospechosa o acusada puede estar detenida ante su puesta a disposición de las autoridades judiciales (detención preventiva/Pretrial Detention);

c. Abogado, defensa letrada y derecho de la persona detenida a la comunicación con miembros de su familia, con el empleador/a y con las autoridades consulares; derecho a informar a las autoridades consulares; a la atención médica urgente;

d. Abogado, defensa letrada y garantías especiales para acusados o sospechosos especialmente vulnerables (el caso de los menores).

2. El derecho de acceso al abogado y a la asistencia letrada en los procesos penales. Incluye las siguientes disposiciones:

a. Disposiciones que regulan el derecho de los sospechosos y los acusados y las personas sujetas a una Orden de Detención Europea (European Arrest Warrant) (Decisión Marco del Consejo de 13 de junio de 2002) y derecho a acceder a un abogado en los procesos penales en su contra: así, este derecho resultó determinante para la dilucidación del llamado caso Melloni (Sentencia del Tribunal de Justicia de la Unión Europea de 26 de febrero de 2013, C-399/11, y STC 26/2014, de 13 de febrero de 2014);

b. Disposiciones para asegurar el derecho a la comunicación con el abogado de los sospechosos y acusados privados de libertad; 
c. Disposiciones para asegurar el acceso al abogado:

c.1 Antes del comienzo del interrogatorio por parte de la policía o cualquier Law Enforcement Agency

c.2 Durante el procedimiento de recogida de pruebas (a nos er que perjudiquen la obtención de pruebas)

c.3 Desde que se produzca la privación de libertad

c.4 Contenido del derecho:

- derecho a recurrir con el abogado que represente en cada caso la defensa letrada;

- derecho a cuantas reuniones (duración y frecuencia adecuadas) exija la aseguración del ejercicio efectivo del derecho a la defensa;

- derecho a la asistencia letrada en interrogatorios y audiencias (con las excepciones contempladas para asegurar la investigación en marcha y/o evitar la destrucción de pruebas);

- derecho a la asistencia letrada en actos de investigación o recogida de pruebas en los que la ley nacional del Estado miembro exija o permita la presencia del sospechoso o acusado;

- derecho a la asistencia en el lugar de la detención (caso de que no se trate de detención en el acto de comisión de un delito flagrante).

3. El derecho a recibir asistencia jurídica gratuita (legal aid) y condiciones para obtenerla (la insuficiencia de recursos para litigar).

La propuesta de Directiva de la Comisión prevé, en casos tasados, la posibilidad de ejecutar la renuncia al derecho de acceso a abogado. De conformidad con la jurisprudencia del TEDH (ver SSTEDH), se exige que la renuncia responda a circunstancias objetivadas, ser voluntaria e inequívoca en la expresión del consentimiento a la misma, y expresada con conocimiento de su alcance y capacidad acreditada para conocer las consecuencias de esa renuncia.

La Directiva establece el reconocimiento del «derecho a la comunicación con la defensa de su elección» (salvo provisión de oficio), a efectos de información además de a la persona (familiar o empleador/a) o lo que desee contactar.

En caso de que el detenido sea extranjero, se prevé asimismo el derecho a comunicar en el Consulado o Embajada del Estado miembro de su nacionalidad.

No se prevén excepciones respecto a la comunicación con abogado. Sí se recoge en la Jurisprudencia del TEDH un margen tasado de excepción en la fase inicial de los procesos penales.

En efecto, el TEDH ha establecido que el derecho de acceso al abogado puede no ser «absoluto» en la legislación nacional sin contravención del CEDH. 
Ahora bien, toda excepción debe ser tasada, limitada estrictamente en su duración temporal, y no afectar en ningún caso al derecho fundamental a ser oído en el proceso en condiciones de imparcialidad y prohibición de indefensión.

Así pues, los EE. MM. sólo pueden establecer excepciones al derecho de acceso al abogado en «circunstancias excepcionales, concretamente justificadas y con las garantías procesales necesarias». Debe justificarse toda excepción por razón «imperiosa» relacionada con la «urgente necesidad de evitar un peligro para la integridad física de una o más personas». Debe ajustarse además al principio de proporcionalidad (art. 52 CDFUE), de modo que la autoridad competente debe optar por la opción de la medida que menos restrinja el derecho de acceso a un abogado. Por su parte, la duración de tal medida debe durar el mínimo posible.

Otra limitación establecida por el TEDH consiste en que «ninguna excepción puede basarse exclusivamente en el tipo penal de la incriminación concreta o la gravedad del delito». Toda excepción exige, antes bien, una ponderación individualizada de las circunstancias del caso (case by case strict scrutiny). Ninguna excepción debe enervar (hacer inviable) la imparcialidad del juicio justo, ni perjudicar el derecho fundamental del sospechoso o imputado a permanecer en silencio o declarar en su contra. Ninguna declaración en ausencia de su abogado puede ser tampoco utilizada en su contra.

De modo que toda excepción, conforme a la Directiva, sólo procederá siempre y cuando sea debidamente validada por resolución motivada de la autoridad judicial. Prevalece la prohibición que la excepción puede ser impuesta motu proprio por la policía o por las Law Enforcement Agencies que no revistan la categoría de «autoridad judicial independiente e imparcial» conforme a los criterios establecidos en la Jurisprudencia del TEDH.

No cabe ninguna excepción — siguiendo la Jurisprudencia del TEDHrespecto de la regla firme que asegura en todo caso la comunicación de todo sospechoso o acusado con su abogado (con independencia de la forma que esa comunicación adopte), como elemento integrante del contenido esencial del derecho de defensa y de asistencia letrada.

\section{La jurisprudencia del Tribunal de Justicia de la Unión Europea y del Tribunal Europeo de Derechos Humanos sobre el derecho a la defensa y a la asistencia letrada y el derecho a un juicio justo}

El TL no solamente ha asumido expresamente los estándares del CEDH como elemento componente de los «principios constitucionales comunes» y de 
las «tradiciones constitucionales» del Derecho de la UE, tal y como han sido interpretados por la Jurisprudencia del TEDH con sede en Estrasburgo (arts. 2.3 y 6 TUE, según el TL).

Además de hacer esto, el TL incorpora un mandato de incorporación de la UE al CEDH y de sometimiento de los actores de la UE a los estándares jurisprudenciales del TEDH (art. 6 TUE). Con arreglo a este mandato, las instituciones europeas - mandato del Consejo, negociación por la Comisión y consentimiento del PE_ llevarán adelante un complejo proceso de negociación a todo lo largo de la Legislatura 2009-2014.

Pues bien, el TJ emitió, el 18 de diciembre de 2014, un importante Dictamen (opinión consultiva) desfavorable al mandato de ratificación adoptado por unanimidad en los EE. MM. (contrario a la opinión favorable de los servicios jurídicos de la Comisión y PE, desoyendo incluso la recomendación favorable del Abogado General). De modo que, tras tantos años de arduas negociaciones y vicisitudes entre las dos esferas de integración europea - Consejo de Europa y UE_- en la Legislatura 2014-2019 continúa aún pendiente el cumplimiento del mandato de ratificación del CEDH por parte de la UE establecido en el art. 6 TUE.

En este contexto, todavía movedizo y pendiente de los desarrollos y evoluciones que puedan desprenderse de la negociación para cumplir los parámetros y exigencias establecidos en la antes referida avis consulta del TJ, deben tenerse presente los arts. 47 a 50 de la CDFUE — derechos fundamentales de los europeos operativos en el ámbito del derecho a la defensa o un juicio justo y equitativo con todas las garantías, como los arts. 5 y 6 del CEDH (Derecho de Libertad, régimen de la detención y acceso a un juicio justo), incidente sobre los ámbitos concomitantes en el cúmulo concéntrico, aunque más amplio (47 Estados) del Consejo de Europa.

Por su parte, la Jurisprudencia del TEDH ha elaborado una amplia doctrina en desarrollo de los siguientes derechos del CEDH: a) derecho a ser informado de las causas de la detención y de la acusación en su contra en una lengua comprensible (derecho a la interpretación y traducción de documentos); b) Derecho a la defensa (asistencia letrada con todos los medios pertinentes para la preparación de la defensa, y condiciones y límites de la denuncia a este derecho); c) Derecho a la asistencia jurídica gratuita (con criterios que dirimen la insuficiencia de medios económicos y los «intereses de la Justicia»); d) Derecho a la presunción de inocencia, a no declarar (permanecer en silencio) y a no declarar contra uno mismo (against self incrimination); e) Derechos procesales (especialmente incidentes en el proceso penal): límite a la prisión provisional y derecho a estar presente y tomar parte en el proceso; derecho a la «Igualdad de armas» y 
a los medios de prueba pertinentes; derecho a una resolución motivada y derecho a la revisión judicial (appeal, jucidial review) en toda sentencia condenatoria en primera instancia.

1) El derecho a ser informado

En cuanto al derecho a ser informado de la acusación en su contra, la Jurisprudencia del TEDH desarrolla el principio de protección de la persona sospechosa, detenida o acusada frente a la vulnerabilidad de una información insuficiente acerca de la naturaleza de los cargos o materiales probatorios (evidence) contra ellos. Casos Padadow vs Bulgaria (2006), Campbell and Fell vs UK (1984), Fox, Campbell and Hartley vs UK (1990), Shamayev vs Rusia (2005) y Saadi vs UK (2008).

El derecho a ser informado acerca de las pruebas en su contra, y a preparar deliberadamente la defensa ante las mismas, en Garcia Alva vs Alemania (2009), Öcalan vs Turquía (2005), Moiseyev vs Rusia (2008), Dragicevic vs Croacia (2012).

El derecho a la defensa — clave de bisada de los derechos procesales del sospechoso o acusado - incluyen el derecho a representarse a sí mismo: Croissant vs Alemania (1982). Ocupa un lugar central el derecho a la asistencia letrada desde el inicio de las investigaciones: Salduz vs Turquia (2008); Zaichenko vs Rusia (2010); Brusco vs Francia (2010); Stanca vs Rumanía (2012), Simons vs Bélgica (2012).

El derecho a la interpretación y traducción de documentos en una lengua que sea comprensible al acusado, no exonera completamente de sus costas, pero no consiente tampoco repercutir íntegramente las mismas sobre acusado al final del proceso: Brosikev vs Italia (1981), Conka vs Bélgica (2002), Salian vs Rumanía (2008), Luedicke vs Alemania (1988).

El derecho a la consulta confidencial (private consultation) con abogado desarrolla el derecho a la comunicación confidencial (no sujeta a vigilancia ni a intercepción por terceros) con la defensa letrada como esencial para aseguramiento del derecho a un juicio justo. Así, Brennan vs UK (2001); Sakhnovsky vs Rusia (2010). Conecta con el derecho a preparar adecuadamente y con el tiempo necesario los medios de la propia defensa, debiendo ser proporcional a las circunstancias del caso y a su complejidad. Boisova vs Bulgaria (2008), Luchaninova vs Ucrania (2011); Miniposhvili vs Rusia (2011). Por supuesto, el derecho a la renuncia a la asistencia jurídica recibe una delimitación rigurosa restrictiva, tendente a la aseguración de que se conocen las consecuencias y se adopta libremente la decisión en pleno conocimiento de sus implicaciones: Padadow vs Bulgaria (2006), Salstyan vs Armenia (2007). 
2) El derecho a la asistencia jurídica

He aquí otro de los derechos fundamentales incidentes en el proceso penal, instrumental para la efectividad del derecho a un juicio justo con todas las garantías. Se aplica a la interpretación de este derecho criterios económicos (insuficiencia de recursos para litigar) de acuerdo con las circunstancias y complejidad del caso. Twalib vs Grecia (1998), Morris vs UK (2002), Maskimenko vs Ucrania (2011). También se tendrán en cuenta el criterio de interés de la «Justicia»; Bifa vs Gracia (2000), Berlinski vs Polonia (2002), Barsom y Varli vs Suecia (2008); Timeyaliyev vs Rusia (2008).

La calidad y caracteres a la asistencia letrada reciben interpretación en la SSTEDH Davol vs Portugal (1998); Orlov vs Rusia (2011); Moldoveanu vs Rumania (2012).

La libre elección del abogado y la asistencia letrada puede someterse a límites e interés de la Justicia, así como que los criterios con los EEMM proveen a la garantía de un servicio de asistencia gratuita o defensa de oficio. Van Ulden vs Paises Bajos (1997); Krempovskij vs Lituania (1999); Erdem vs Alemania (1999); Leyerblom vs Suecia (2003).

3) El derecho a la presunción de inocencia y a permanecer en silencio

Desarrolla el principio de protección del derecho a no declarar contra sí mismo y a no confesarse culpable en relación con la prohibición de tortura y de cualquier tratamiento «inhumano, cruel o degradante» en el curso de la investigación de los procesos penales.

La presunción de inocencia (art. 6.2 CEDH) vierte la carga de la prueba sobre la acusación, consagra el beneficio de la duda a favor del acusado (in dubio pro reo) y proclama su violación cuando se privilegia procesalmente el atestado de funcionarios públicos (policía, fiscal o juez) frente a la destrucción por medio de prueba pertinente de la presunción de inocencia. Así, Barbera, Meseguer, J Carlo vs España (1998), Telfner vs Austria (2001), Phillpis vs UK (2001), Falk vs Paises Bajos (2004).

La particular concreción de la garantía procesal de la no autoincriminación y del derecho a permanecer en silencio se extiende a documentos y testigos de la acusación. Funke vs Francia (1993), Heancy y McGuinnes vs Irlanda (2000), Zaichenko vs Rusia (2010).

4) Los derechos procesales en el juicio oral

Garantizan el acceso a una defensa efectiva mediante la interconexión de los derechos procesales: estar presente en el juicio, igualdad de armas, prueba per- 
tinente, resolución motivada, y recurso contra toda sentencia desfavorable en primera instancia.

El derecho a la limitación de la prisión provisional depende de la gravedad de la acusación y la posibilidad de medidas cautelares alternativas y menos gravosas para la libertad (fianza económica o aseguramiento de pruebas). Neumeister vs Austria (1968); McKay vs UK (2006), Borotyuk vs Ucrania (2010); Michaelko vs Eslovaquia.

El derecho a estar presente y a participar en el proceso: Colozza vs Italia (1998), Poitromoi vs Francia (1993), Cola vs Países Bajos (2004), Bottes vs Noruega (1996), Medenica vs Suiza (2001), Sejdovic vs Italia (2006).

El derecho a la igualdad de armas (presentación de pruebas y testigos de la defensa) puede ser delimitado en aras de los intereses de la Administración de justicia pero debe asegurar el esclarecimiento de los hechos y la determinación de la responsabilidad penal. El TEDH ha establecido un test con tres elementos: a) el rechazo de una declaración testifical debe justificarse con una motivación fundada; b) el testimonio de un testigo en ausencia no puede ser por si solo decisivo para una sentencia condenatoria, c) debe asegurarse una ponderación equilibrada para la valoración fundamental de cada prueba. Isquio vs Italia (1991), Van Mechelen vs Paises Bajos (1997), Polyakov vs Rusia (2009), Korner y Karperko vs Ucrania (2010), Al Khawaja y Tabery vs UK (2011); Kokonenko vs Rusia (2011).

El derecho a una decisión motivada debe asegurar la audiencia de todas las partes y la oportunidad de recurrir sentencias desfavorables (con independencia de las circunstancias del caso, lo que incluye el comportamiento de las partes a lo largo de la investigación y el proceso, la relevancia de los precedentes y la especificidad de los ordenamientos jurídicos de los EEMM). Suominen vs Finlandia (2008); Gradinar vs Moldavia (2008).

El derecho al recurso no obliga a los EEMM a establecer en todos los casos un recurso de casación, pero si a una adecuada garantía procesal frente a sentencias penales desfavorables. Khalfaoui vs Francia (1999); Krombach vs Francia (2001).

\section{5) Conclusión}

La Jurisprudencia del TEDH se construye para fortalecer los derechos procesales de toda persona en las actuaciones tendentes a la investigación de los delitos y a la determinación de la responsabilidad, en un proceso penal con todas las garantías. El derecho al abogado, a la defensa letrada y a la asistencia judicial ante la insuficiencia de recursos para litigar, resalta con claridad esta jurisprudencia como un elemento esencial para asegurar el acceso a un «juicio justo»y al debido proceso (art. $6 \mathrm{CEDH}$ y art. $48 \mathrm{CDFUE}$ ). 


\section{Algunas reflexiones conclusivas}

1. En conclusión, el desarrollo de un Espacio Europeo de Justicia Penal requiere la definición autónoma de los «delitos graves» que operan como referencia de la intervención del PE como legislador europeo en materia penal. Ahora bien, el parámetro de esa ambición depende tanto de la aplicación concreta de mecanismos nacionales (test de subsidiariedad) como del arraigo común de principios compartidos: los de necesidad y proporcionalidad de la intervención europea.

2. Dicho esto, resulta esencial preservar la conciencia activa de los derechos de la ciudadanía europea como inspiración del objeto de estas páginas: la configuración de un Espacio de Justicia Penal. Esta ambición proclamada del TL (arts. 67 a 89 TFUE) no puede ser completada con éxito a menos que se comprenda en plenitud y complitud el horizonte descrito por la entrada en vigor de la CDFUE «con el mismo valor jurídico que los Tratados» (art. 6 TFUE).

3. Todo esto quiere decir que la definición del alcance del Espacio Europeo de Justicia Penal exige un enfoque «principal»: bien porque la intervención de alcance europeo sea exigible para la adecuada protección de los intereses de la UE, bien porque — superado el test de la proporcionalidad, necesidad y subsidiariedad - la UE puede acreditar un título habilitante indiscutible a la hora de legitimar la acción del PE como del legislador penal europeo (art. 83 TFUE).

4. Nada de esto podría completarse con éxito a menos que se perfile con fuerza motriz irresistible de legitimación de origen que sólo puede conferir la conciencia de sus derechos por parte de la ciudadanía europea, o, lo que es decir lo mismo, de los 500 millones de ciudadanos europeos. La superación de prejuicios nacionales, residuo de «soberanía» y «regalía estatal» en la materia penal, «identidades nacionales» (art. 4 TUE) e incluso de las diferencias tanto orgánicas, institucionales como procedimentales, resulta crucial para apuntar una «gobernanza europea» de la Justicia Penal.

5. La «voluntad europea de Constitución» en materia de legislación penal y cooperación judicial penal (Wille zur Verfassung, en la expresión, en alemán, de Konrad Hesse) resulta, pues, determinante.

Sí, voluntad política. Para la superación de las dificultades. Para la actuación específica. Para la sobreimposición de las instituciones supranacionales a frente a las resistencias opuestas por los obstáculos nacionales. Voluntad para remontar el argumento usual (i.e, la vexata quaestio) de la soberanía celosamente preservada por los EE. MM. en las materias implicadas.

6. Porque la construcción de un Espacio europeo de Justicia Penal en la única vía para remontar los obstáculos de la investigación y de la persecución 
transnacional de delitos más allá de las fronteras y límites territoriales de la jurisdicción de los Estados o nación.

7. Sin duda, debemos ser conscientes de la diferencia marcada por la Justicia Penal respecto de los demás tradicionalmente cubiertos por la «regalía del Estado». Cambian de naturaleza y de «operability» cuando adquieren dimensión transfronteriza, supraestatal, europea. Los derechos de defensa, de protección del menor y personas vulnerables, la representación y participación de las víctimas en estas fases del proceso, testimoniar de manera elocuente la envergadura y problematicidad de la ambición proclamada.

Pero también debemos tener en cuenta el estímulo presupuesto por el acervo acumulado en el antes llamado «III Pilar Europeo», en la Decisión Marco, en la constelación de instituciones y agencias coadyuvantes de la cooperación policial y judicial europea en materia penal (Europol, Eurojust... Embrión de la futurible Fiscalía Europea, EPPO en inglés).

8. De acuerdo con la jurisprudencia del TJ (Kadi Case, 2013) nada de esto podría hacerse con ignorancia o desprecio de los derechos fundamentales proclamados en la CDFUE. Ningún avance relevante podría por tanto producirse en tan importante área con descuido del principio del principio estructural de la cultura del Derecho y los derechos de la ciudadanía que anima la construcción europea desde el momento en que adquirió carta de naturaleza constitucional.

9. En cuanto a la evaluación y perspectivas de evaluación de los objetivos consignados en el art. 82 TFUE (definitorios del «Espacio Europeo de Justicia Penal»), habría que constatar los límites a respetar, en tanto aparecen también explícitamente reflejados en la letra del TL. a) Primero, su coherencia con el objetivo proclamado de «prevención y/o evitación de conflictos» y asignación de competencia jurisdiccional para entender de conflictos entre los EE. MM. y la UE. b) Segundo, la necesidad de apoyarse en la formación judicial y en el ministerio fiscal para la cooperación activa, tanto interestatal (entre EE. MM. de la UE) como paneuropea. Entrenamiento, formación continua y especializada de los profesionales del Derecho y los operadores jurídicos, son condición fundamental de toda perspectiva de éxito. c) Tercero, apuntalamiento de la cooperación entre las jurisdicciones las Law enforcement Agencies a la investigación y persecución de delitos a escala paneuropea.

10. Por último, toda propuesta de desarrollo futuro debe superar prejuicios y resistencias nacionales, mostrar «valor añadido» en el escalón europeo de protección de derechos de rango constitucional, reforzar la libertad e igualdad de las personas de acuerdo con las tradiciones constitucionales comunes, y evitar que los Gobiernos aprovechen las lagunas para escapar las exigencias de sus Constituciones nacionales y del propio Derecho Constitucional europeo. 
Ninguna democracia constitucional que se precie — tampoco, en esto, la europea- puede tolerar la degradación de sus estándares mínimos de reconocimiento so pretexto o a rebufo de la integración europea. La idea es cabalmente la contraria: reforzarla y reforzar la identidad múltiple y compatible de la ciudadanía europea.

El derecho al abogado, el derecho a la defensa, a la asistencia letrada y a la asistencia jurídica se perfilan como garantía instrumental e institucional del contenido esencial de los derechos procesales (arts. 47 a 50 CDFUE) en los procesos penales de la UE.

Asistimos por lo tanto a un paso de gigante en la armonización del garantismo de los derechos de ciudadanía en el ELSJ en la UE, tal y como se le configura en el TL. Y lo es, al mismo tiempo, en el reconocimiento y consolidación del papel determinante del PE como legislador penal, como legislador procesal penal, y como legislador en desarrollo legal de los derechos fundamentales de la ciudadanía europea.

\section{BIBLIOGRAFÍA}

Incluimos aquí una reseña bibliográfica con algunas referencias en lengua castellana acerca de los avances en la construcción de un Espacio Europeo de Justicia Penal, a la armonización de los derechos procesales en la UE, y a la relevancia en ella del derecho al abogado y a la asistencia letrada.

Allegrezza, S., «Los aspectos formales de la Carta de Derechos», en Arangüena Fanego, C. (coord.), Garantías procesales en los procesos penales en la Unión Europeal Procedural safeguards in criminal proceedings throughout the European Union, Lex Nova, Valladolid, 2007, pp. 367-374.

Álvarez García, F. J./Queralt Jiménez, A., «El derecho a la libertad y a la seguridad y su sistema de garantías en el Convenio de Roma: un estándar mínimo europeo (art. 5 CEDH)», en García Roca, F. J./Santolaya Machetti, P. (coords.). Arangüena Fanego, «Nuevas Directivas sobre derechos procesales de sospechosos e imputados en el proceso penal», en Arangüena Fanego, C. (coord.), Cooperación judicial civil y penal en el nuevo escenario de Lisboa, Comares, Granada, 2011, pp. 269-301; Espacio europeo de libertad, seguridad y justicia: últimos avances en cooperación judicial penal, Lex Nova, Valladolid, 2010; «El derecho a la interpretación y a la traducción. Comentario a la Directiva 2010/64/UE del Parlamento Europeo y del Consejo, de 20 de octubre de 2010», Revista General de Derecho Europeo, núm. 24, 2011, 22 pp.; «La efectividad del acceso a la justicia: autodefensa, defensa técnica y asistencia jurídica gratuita», en Calderón Cuadrado, M. ${ }^{a}$ P./ 
Iglesias Buhigues, J. L. (coords.), El espacio europeo de libertad, seguridad y justicia: avances y derechos fundamentales en materia procesal, Thomson Reuters, Aranzadi, Cizur Menor, 2009, pp. 287-332.; «Primera aproximación al derecho a un proceso equitativo y a las exigencias contenidas en el artículo 6.1 CEDH: en particular el derecho de acceso a un tribunal (art. 6)», en García Roca, F. J./ Santolaya Machetti, P. (coords.), La Europa de los Derechos: el Convenio Europeo de Derechos Humanos, CEPC, Madrid, 2009, pp. 259-275.

Arrese Iriondo, M a . N., «Artículo 5. Derecho a la libertad y a la seguridad», en Lasagabaster Herrarte, I., Convenio Europeo de Derechos humanos. Comentario sistemático, Civitas, Madrid, 2009, pp. 97-169.

AzPitarte SÁnchez, M., El Tribunal Constitucional ante el control del derecho comunitario derivado, Civitas, Madrid, 2002.

Balaguer Callejón, F., «Constitucionalismo Multinivel y Derechos Fundamentales en la Unión Europea», en AA. VV., Teoría y metodología del Derecho. Estudios en Homenaje al Profesor Gregorio Peces-Barba, Vol. II, Dykinson, Madrid, 2008, pp. 133-157; «Fuentes del derecho, espacios constitucionales y ordenamientos jurídicos», Revista Española de Derecho Constitucional, núm. 69, 2003, pp. 181-213; «Niveles y técnicas internacionales e internas de realización de los derechos en Europa. Una perspectiva constitucional», ReDCE, núm. 1, 2004 , pp. 25-46. Dirección electrónica: http://www.ugr.es/ redce/.

Calderón Cuadrado, M. ${ }^{a}$ P., «Dimensión europea de los derechos de la defensa: tres proposiciones para un debate y un interrogante sobre su titularidad», en Calderón Cuadrado, M. ${ }^{a}$ P./Iglesias Buhigues, J. L. (coords.), El espacio europeo de libertad, seguridad y justicia: avances y derechos fundamentales en materia procesal, Thomson Reuters, Aranzadi, Cizur Menor, 2009, pp. 173-238.

Cámara Villar, G., «Los derechos fundamentales en el proceso histórico de construcción de la Unión Europea y su valor en el Tratado constitucional», ReDCE, núm. 4, Julio-Diciembre, 2005, pp. 9-42. Dirección electrónica: http://www. ugr.es/ redce/REDCE4/articulos/01camara.htm.

Chicharro Lázaro, A., «El Tratado de Lisboa y el programa de Estocolmo: Los nuevos retos de la cooperación judicial en materia civil», Revista electrónica de estudios internacionales, núm. 20, 2010, pp. 1-36.

De Hoyos Sancho, M., «Armonización de los procesos penales, reconocimiento mutuo y garantías esenciales», en De Hoyos Sancho, M. (coord.), El proceso penal en la Unión Europea: Garantías esenciales, Lex Nova, Valladolid, 2008, pp. 42-79.

Donaire Villa, F. J., «El espacio de libertad, seguridad y justicia tras el Tratado de Lisboa: entre supranacionalidad e integración diferenciada», Revista española de derecho europeo, núm. 35, 2010, pp. 337-364. 
Esparza Leibar, I./Etxeberria Guridi, J. F.,»Artículo 6. Derecho a un proceso equitativo», en Lasagabaster Herrarte, I., Convenio Europeo de Derechos bumanos. Comentario sistemático, Civitas, Madrid, 2009, pp. 170-256.

Fonseca Morillo, F. J., «Algunas reflexiones sobre las perspectivas de la cooperación judicial penal en la Unión Europea tras la entrada en vigor del Tratado de Lisboa», en Arangüena Fanego, C. (dir.), Espacio europeo de libertad, seguridad y justicia: últimos avances en cooperación judicial penal, Lex Nova, Valladolid, 2010, pp. 19-27.

Freixes Sanjuan, T., «Derechos Fundamentales en la Unión Europea. Evolución y prospectiva: la Construcción de un Espacio Jurídico Europeo de los Derechos Fundamentales», ReDCE, núm. 4, julio-diciembre, 2005, pp. 43-86. Dirección electrónica: http://www.ugr.es/ redce/REDCE4/articulos/02freixes.htm.

Gambino, S. (traducido del italiano por FagGiani, V.), «Jurisdicción y justicia entre Tratado de Lisboa, Convenio Europeo de Derechos Humanos y ordenamientos nacionales», ReDCE, núm. 13, 2010, pp. 83-120. Dirección electrónica: http://www.ugr.es/ redce/REDCE13pdf/04Gambino.pdf.

García Roca, F. J./Vidal Zapatero, J. M., «El derecho a un tribunal independiente e imparcial (art. 6.1): una garantía concreta y de mínimos antes de una regla de la justicia», en García Roca, F. J./Santolaya Machetti, P. (coords.), La Europa de los Derechos: el Convenio Europeo de Derechos Humanos, CEPC, Madrid, 2009, pp. 365-407.

GASCón INCHAUSTi, F., «En torno a la creación de un derecho procesal penal europeo», Revista Española de Derecho Europeo, núm. 23, 2007, pp. 371-417.

Jimeno Bulnes, M., «Las implicaciones del Tratado de Lisboa en la cooperación judicial europea en materia penal», en Arangüena Fanego, C. (dir.), Espacio europeo de libertad, seguridad y justicia: últimos avances en cooperación judicial penal, Lex Nova, Valladolid, 2010, pp. 30-70.

Lirola Delgado, I., «La cooperación judicial en materia penal en el Tratado de Lisboa: ¿un posible proceso de comunitarización y consolidación a costa de posibles frenos y fragmentaciones?», Revista General de Derecho Europeo, núm. 16, 2008, págs. 1-25.

Martín y Pérez de Nanclares, J. (coord.), El Tratado de Lisboa. La salida de la crisis constitucional, Asociación Española de Profesores de Derecho Internacional y Relaciones Internacionales, Iustel, 2008, 703 pp.; «El espacio de libertad, seguridad y justicia en el Tratado de Lisboa», Revista de las Cortes Generales, núm. 70-72, 2007, pp. 85-126.

Montero Aroca, J., «Derecho a un juez independiente e imparcial», en Calderón Cuadrado, Ma. P./Iglesias Buhigues, J. L. (coords.), El espacio europeo de libertad, seguridad y justicia: avances y derechos fundamentales en materia procesal, Thomson Reuters, Aranzadi, Cizur Menor, 2009, pp. 101-132. 
Muerza Esparza, J. J., «Derechos de la defensa», en Calderón Cuadrado, M. ${ }^{a}$ P./ Iglesias Buhigues, J. L. (coords.), El espacio europeo de libertad, seguridad y justicia: avances $y$ derechos fundamentales en materia procesal, Thomson Reuters, Aranzadi, Cizur Menor, 2009, pp. 149-169.

PARdo Iranzo, V., «El derecho a la interpretación y traducción gratuitas», en Calderón Cuadrado, M. ${ }^{a}$ P./Iglesias Buhigues, J. L. (coords.), El espacio europeo de libertad, seguridad y justicia: avances y derechos fundamentales en materia procesal, Thomson Reuters, Aranzadi, Cizur Menor, 2009, pp. 361-391.

Parra García, J. L., «La interpretación y traducción en el ámbito de la cooperación judicial de la UE», en ORTEGa ARJONILla, E., La traducción e interpretación jurídicas en la UE. Retos para la Europa de los ciudadanos, Comares, Granada, 2008, pp. 711-732.

Pascual Serrats, R., «El derecho a ser informado de la acusación (una aproximación al mismo a través de la jurisprudencia del TEDH)», en Calderón Cuadrado, M. ${ }^{a}$ P./Iglesias Buhigues, J. L. (coords.), El espacio europeo de libertad, seguridad y justicia: avances y derechos fundamentales en materia procesal, Thomson Reuters, Aranzadi, Cizur Menor, 2009, pp. 239-254.

Perelló Doménech, I., «El derecho a ser informado(a) de la acusación (art. 6.3.a) CEDH», en García Roca, F. J./Santolaya Machetti, P. (coords.), La Europa de los derechos: el Convenio Europeo de Derechos Humanos, op. cit., pp. 479-493.

Pernice, I., «Multilevel constitutionalism and the Treaty of Amsterdam: European Constitution-making revisited?», Com. Mark. Law Rev., núm. 4, 1999, pp. 703-750.

- «Multilevel constitutionalism in the European Union», Eur. Law Rew., núm. 5, 2002, pp. 511-529.

Rolla, G., «La Carta de Derechos Fundamentales de la Unión Europea en una perspectiva comparada. Técnicas de codificación y cláusulas de interpretación», ReDCE, Ejemplar dedicado a: Homenaje a Peter Häberle (I), núm. 11, 2009, pp. 135-164. Dirección electrónica: http://www.ugr.es/ redce/REDCE11pdf/05_ GIANCARLO\%20ROLLA.pdf.

- «La Carta de Derechos Fundamentales de la Unión Europea y el Convenio Europeo de los Derechos Humanos y de las Libertades Fundamentales: su contribución a la formación de una jurisdicción constitucional de los derechos y las libertades», Revista europea de derechos fundamentales, núm. 15, 2010, pp. 15-39.

SÁrz Arnaiz, A., «El Tribunal de Justicia, los Tribunales Constitucionales y la tutela de los derechos fundamentales en la Unión Europea: entre el (potencial) conflicto y la (deseable) armonización: de los principios no escritos al catálogo constitucional, de la autoridad judicial a la normativa», en Gómez Fernández, I. (coord.)/ Cartabia, M. (dir.)/De Witte, B. (dir.)/Pérez Tremps, P. (dir.), Constitución europea y constituciones nacionales, Tirant lo Blanch, Valencia, 2005, pp. 531-588. 
Title:

THE EUROPEAN PARLIAMENT, LEGISLATOR OF THE EUROPEAN SPACE OF CRIMINAL LAW

\title{
Summary:
}

I. The european parliament as criminal legislator. Towards a european space of criminal law. II. The european parliament as legislator on issues of criminal procedural law and the right to defence in criminal proceedings.

\section{Resumen:}

Este artículo tiene por objeto analizar la emergencia y posteriores desarrollos de un Espacio de Justicia Penal Europeo a la luz de la entrada en vigor del Tratado de Lisboa y sus implicaciones respecto del nuevo papel del Parlamento Europeo como colegislador ordinario en este campo tradicionalmente reservado a la soberanía de los Estados. Se analiza el art. 83 del TFUE, base jurídica para la «lisbonización» del Derecho Penal Europeo, anteriormente situado en el llamado «Tercer Pilar». Se abordan los retos pendientes en el Espacio de Justicia Penal Europeo, así como el papel del Parlamento Europeo como colegislador ordinario en cuestiones de índole procesal penal relativas al derecho a la defensa y a las garantías procesales. Se analiza la incardinación de estos derechos procesales en la Carta Europea de Derechos Fundamentales y en el llamado Programa de Estocolmo, que desarrolla el Espacio de Libertad, Seguridad y Justicia de la UE. Se describe el contenido de los derechos procesales de las personas sospechosas y del acusado en el proceso penal en la UE y del derecho al abogado, a la defensa letrada y a la asistencia jurídica gratuita. Finalmente, se revisa la jurisprudencia del Tribunal de Justicia de la UE y del Tribunal Europeo de Derechos Humanos sobre el derecho a la defensa, a la asistencia letrada y el derecho a un juicio justo con todas las garantías.

\begin{abstract}
:
This article aims at analysing the emergence and subsequent developments of the European Space of Criminal Law in the light of the entry into force of the Lisbon Treaty and its implications regarding the new role played by the European Parliament as a fully-fledge colegislator in this field. It approaches art. 83 of the TFEU as the legal basis allowing for the «lisbonisation» of the European Criminal Law, previously lying within the former so-called «Third Pillar». The
\end{abstract}


remaining challenges in the field of EU Criminal law are also addressed as well as the role of the EP as colegislator on issues of criminal procedural law encompassing defence rights and procedural rights. The incorporation of these procedural rights in the ECFR and in the so-called Stockholm Programme, which develops the area of Freedom, Security and Justice within the EU, is also assessed. The content of the procedural rights of suspects or accused persons in criminal proceedings, the right to access to a lawyer and to adequate legal aid is also outlined. Finally, the case-law of the European Court of Justice and the European Court of Human Rights on due process, and the right to legal advice, before and at a trial, is analysed.

\section{Palabras claves:}

Espacio Europeo de Justicia Penal, Legislador Penal Europeo, Derecho Penal Europeo, Garantías Procesales, Derecho a la Defensa, Asistencia Letrada, Asistencia Jurídica Gratuita, Carta de Derechos Fundamentales de la UE.

\section{Key words:}

European Space of Criminal Justice, European Criminal lawmaker, Procedural Safeguards, Procedural Rights, Right to access to a Lawyer, Right to Legal Aid, European Charter of Fundamental Rights. 